\title{
Control de constitucionalidad y consulta legislativa ¿Hacia un sistema mixto de control federal?
}

\section{Control of Constitutionality and Legislative ConsultationTowards a Mixed System of Federal Control?}

Jorge Alejandro Amaya* https://orcid.org/0000-0003-2292-0126

http://dx.doi.org/10.21503/lex.v18i26.2191

* Doctor y posdoctor en derecho (área constitucional) de la Universidad de Buenos Aires. Profesor regular adjunto de dicha universidad. Profesor de posgrado y doctorado de la UBA. Co Director de los Cursos de Profundización en Derecho Constitucional que dicta en Latinoamérica la Universidad de Bolonia (Italia). Vocal titular del Comité Directivo de la Asociación Argentina de Derecho Constitucional y vicepresidente de la Asociación Argentina de Derecho Procesal Constitucional. Argentina.

Correo electrónico: jaamaya@fibertel.com.ar, jaamaya@jaamaya.com.ar

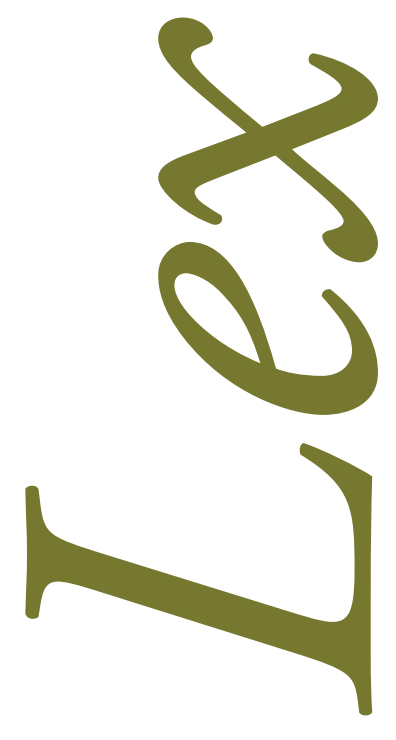




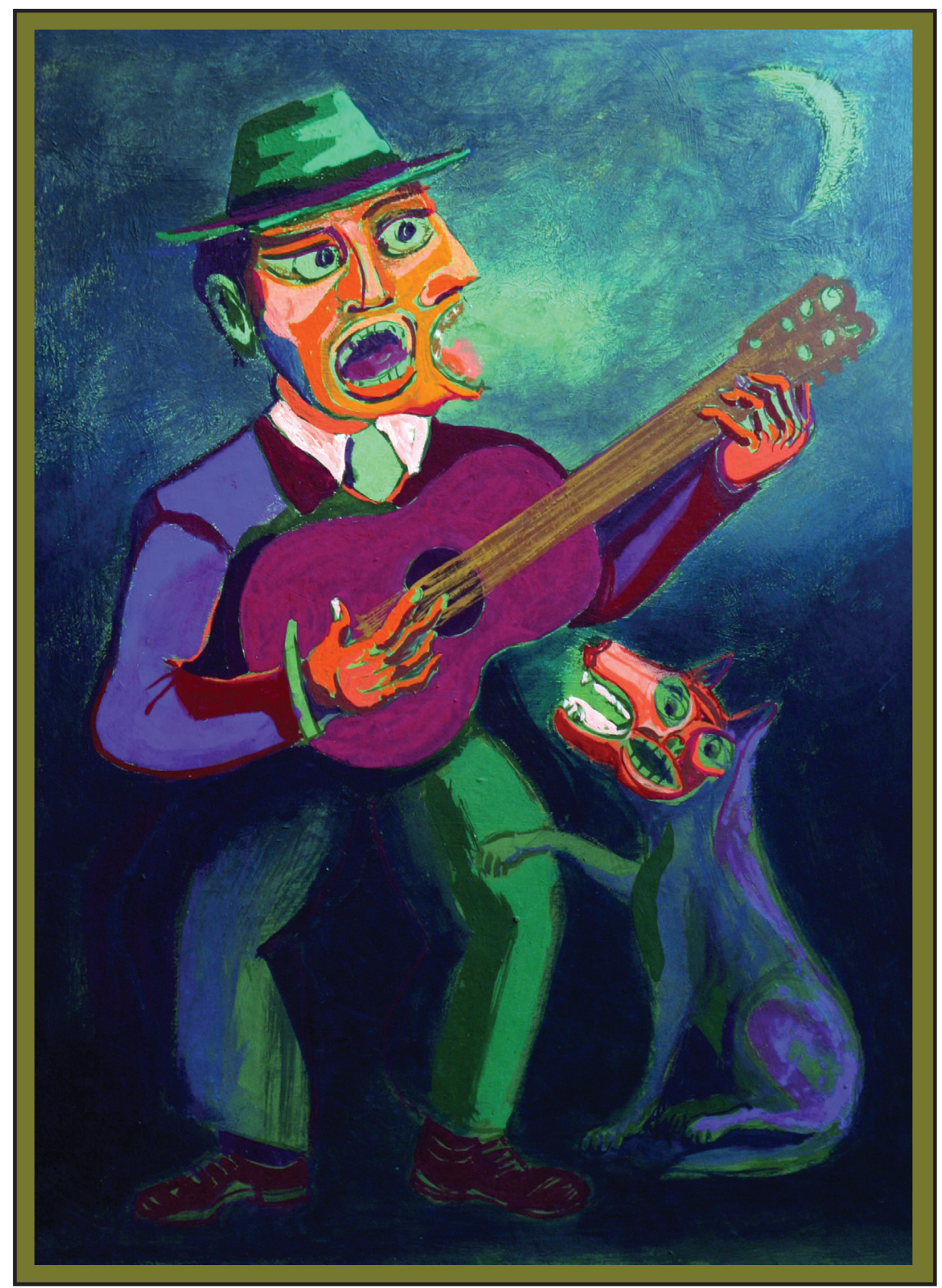

Serenata. Mixto, 1994. Artista plástico peruano, Alberto Quintanilla (Cusco, 1934). 


\section{RESUMEN}

El artículo hace un análisis sobre el control constitucional y consulta legislativa y el posible cambio a un sistema mixto de control federal en la Argentina. Primero hace reflexiones previas; analiza los modelos y sistemas de control de constitucionalidad, sus reglas, características, e identidad; la convergencia de los modelos; los sistemas Latinoamericanos, los sistemas mixtos; los sistemas provinciales argentinos. Sistemas mixtos; el sistema federal argentino, reglas, excepciones y principios, algunas dificultades actuales; las consultas previas de constitucionalidad: un recorrido por el derecho comparado; el caso "Fernández de Kirchner Cristina en carácter de Presidenta del H. Senado de la Nación s/acción declarativa de certeza y la sentencia de la CSJN: Como decir sí, diciendo no; a modo de conclusión se pregunta hacia donde van ¿Hacía un sistema mixto de control?

Palabras clave: control de constitucionalidad, modelos y sistemas de control: difuso, concentrado y mixt, identidad de los sistemas, el sistema argentino, consultas previas de constitucionalidad.

\section{ABSTRACT}

The article analyzes the constitutional control and legislative consultation and the possible change to a mixed system of federal control in Argentina. First he makes preliminary reflections; analyzes the models and systems of constitutionality control, their rules, characteristics, and identity; the convergence of models; Latin American systems, mixed systems; Argentine provincial systems, Mixed systems; the Argentine federal system, rules, exceptions and principles, some current difficulties; prior consultations on constitutionality: a journey through comparative law; the case "Fernández de Kirchner Cristina as President of the Senate of the Nation on declarative action of certainty and the judgment of the CSJN: How to say yes, saying no; By way of conclusion, it is asked where they are going. Was there a mixed control system?

Key words: constitutionality control, control models and systems: diffuse, concentrated and mixed, identity of the systems, the Argentine system, prior consultations on constitutionality. 
“...no vaya a resultar que los criterios de un máximo

Tribunal de Justicia estén en la misma clase que los boletos del ferrocarril: válidos para este viaje y día solamente"1

\section{INTRODUCCIÓN Y REFLEXIONES PREVIAS}

La pandemia de COVID-19 que justificó la declaración de emergencia sanitaria y el aislamiento social preventivo y obligatorio dispuesto inicialmente por el DNU No 297/2020 a fin de proteger la salud pública, ha tenido un resultado exitoso hasta el momento - desde la perspectiva epidemiológicaen comparación con los países más castigados de Europa y América.

Pero el virus no solo ha puesto en alerta a la sanidad, sino también alterado el sistema constitucional argentino como nunca habíamos visto desde el retorno de la democracia, causando alarmantes efectos institucionales ${ }^{2}$.

Basta como ejemplo más palmario la desarticulación del sistema de división de poderes, reflejado en la notoria inacción del Poder Legislativo por meses, y la reducción del servicio de justicia a su mínima expresión, derivada de la declaración de feria judicial dispuesta por la Corte Suprema de Justicia de

1. Del justice Roberts en Grovey v. Townsend, 295 U.S. 45 (1935).

2. En nombre de la "salud pública" y con justificación en la "pandemia" se dictaron, entre otras medidas, más de setenta decretos presidenciales solamente durante el mes de marzo, acaparando exclusivamente el Presidente la tarea legislativa en la emergencia. Lo mismo ha sucedido en las Provincias y los Municipios, cuyos Poderes Ejecutivos han llegado a bloquear sus límites territoriales o rutas de tránsito, desconociendo que no existen barreras interprovinciales y restringiendo arbitrariamente varios derechos constitucionales. Algunas provincias y Municipios establecieron toque de queda, derivando en una limitación tan estricta del derecho de circulación que posicionan las medidas en contraposición al art. $28 \mathrm{CN}$ que establece que los principios y garantías que la Constitución establece no podrán ser alterados por las leyes que reglamentan su ejercicio. Se ha llegado incluso en algunas provincias y municipios a colocar fajas en los domicilios de infectados, configurando un acto discriminatorio; y a auspiciar la denuncia social de quienes supuestamente infringen el aislamiento obligatorio, con consecuencias imprevistas de enfrentamiento social. A través del Decreto PEN 457/2020 se suspendió el límite del 5\% que establece el art. 37 de la ley de administración financiera, restaurándose los tristemente célebres "superpoderes". Claramente el Estado de Derecho ha sido puesto en cuarentena. 
la Nación (CSJN) y sus sucesivas ampliaciones (hoy regularizándose en algunos sectores del país) y la prohibición de trabajo (en condiciones habituales) dispuesta a los abogados por la normativa de emergencia en el ámbito de la justicia nacional y federal.

En este marco, el Senado de la Nación dispuso por resolución RSA-548/2020 (renunciando desde mi perspectiva a su responsabilidad institucional) adherir a la normativa del aislamiento social, preventivo y obligatorio dispuesto por el DNU No 297/2020, a pesar que el art. 6 o del mismo establecía que quedaban exceptuados de dicho aislamiento las actividades consideradas esenciales en la emergencia a los fines del cumplimiento de sus actividades, entre las cuales se encontraban las autoridades superiores de los gobiernos nacional, provincial y municipal y los trabajadores del sector público convocados para garantizar las actividades requeridas por las respectivas autoridades (art. $6^{\circ}$ punto 2.), debiéndose interpretar en una república $\left(\operatorname{art} .1^{\circ} \mathrm{CN}\right)$ el concepto de "gobierno" como referido a los tres poderes del Estado (no creo que esta última afirmación necesite mayor aclaración).

Es que, si avaláramos la resolución del Senado y su neutralización institucional con fundamento en el cuidado de la salud de sus integrantes, considerando que su mayoría cuenta con más de 60 años, como en declaraciones públicas se adujo, el Presidente y el Ministro de Salud, dos de los actores principales en esta época de pandemia, deberían haber corrido la misma suerte.

Las épocas de excepción justifican el ejercicio intenso de facultades constitucionales de los poderes, pero también ponen a prueba la fortaleza del sistema constitucional que rige un país; y la templanza de sus gobernantes.

Dentro de las tantas anomalías constitucionales que el estado de excepción actual ha despertado ${ }^{3}$, se cuenta la acción declarativa de certeza planteada por la Presidenta del Senado de la Nación ante la CSJN con el patrocinio de la Directora de Asuntos Jurídicos del Alto Cuerpo, interrogándola con urgencia y premura de "escribir la historia con sangre o razones" ${ }^{4}$, sobre la validez constitucional que el Senado sesione en forma virtual a tenor de la interpretación del artículo 30 de su reglamento en cuando dice "Los senadores constituyen Cámara en la sala de sus sesiones y para los objetos de su mandato, salvo en casos de gravedad institucional".

Hecha pública la acción y sometida al análisis de los juristas, la gran mayoría, con pocas excepciones ${ }^{5}$, se inclinó por la improcedencia formal y sustancial del planteo.

3. Como alerta el filósofo sur-coreano Byung-Chul Han son muchos los riesgos sociales y políticos para la democracia y los derechos que puede dejar esta pandemia. Ver entrevista publicada en Infobae el 17/05/2020.

4. La abogada patrocinante de la acción, Graciana Peñafort, Directora de Asuntos Jurídicos del Senado, emitió de su cuenta de twiter el 21 de abril la siguiente opinión: "Es la Corte Suprema quien tiene que decidir ahora si los argentinos vamos a escribir la historia con sangre o con razones. Porque la vamos a escribir igual". "Como cantan los Redondos: Fíjate de qué lado de la mecha te encuentras".

5. Contamos entre las mismas, las opiniones de Domingo Rondina; Andrés Gil Domínguez; y Roberto Gargarella. 
La CSJN emitió su pronunciamiento sobre el interrogante en fecha 24/04/2020 rechazando formalmente el pedido, pero expidiéndose afirmativamente obiter dicta a través de un voto de mayoría formado por la opinión de los Ministros Lorenzetti, Maqueda y Highton; un voto concurrente del Juez Rosatti; disintiendo parcialmente el Presidente del Tribunal, Dr. Rosenkrantz.

En pocas palabras, y contrariamente al sentido de lo informado por la mayoría de los medios de comunicación, la CSJN respondió al interrogante con un "si" diciendo "no", es decir, decidiendo afirmativamente por la negativa, reproduciendo de esta manera la estructura de las sentencias de los precedentes Marbury v. Madison (1803) y su símil Sojo (1887) a los cuales refiere en su sentencia, con llamativa poca precisión al referirse al señero fallo norteamericano ${ }^{6}$.

¿Constituye el fallo una excepción en el marco del Estado de excepción? ¿Un boleto válido para un solo viaje y día solamente? ¿O implica el reconocimiento de necesarios cambios en el sistema de control y de reglar -desde nuestra perspectiva- con mayor precisión sus competencias?

\section{MODELOS Y SISTEMAS DE CONTROL DE CONSTITUCIONALIDAD}

Una primera aproximación a las teorías del control de constitucionalidad, indica la conveniencia de distinguir los conceptos de modelos y sistemas de control.

Cuando hablamos de modelos referimos a los mecanismos de control de la supremacía constitucional surgidos a partir de presupuestos históricos, filosóficos, y políticos, definidos y propios ${ }^{7}$, que depositaron esta tarea central del constitucionalismo- en un órgano externo al poder legislativo ordinario.

El modelo judicial difuso o de la judicial review, surgido en los Estados Unidos alrededor del debate existente en torno a la célebre sentencia Marbury v. Madison $(1803)^{8}$; el concentrado o kelseniano,

6. El voto de mayoría afirma erróneamente en el considerando $5^{\circ}$ último párrafo que la causa “... ya se había vuelto abstracta, dado que al momento de dictarse la sentencia el mandato de William Marbury como juez de paz del distrito de Columbia ya había terminado". El mandato de los jueces que presentaron el mandamus era de cinco años. Fueron designados por el Presidente Adams el 2 de marzo de 1801 y ratificados por el Senado inmediatamente. Ante la negativa del nuevo Presidente (Jefferson) de notificarles la designación, interpusieron demanda en diciembre de 1801 y la sentencia se dictó el 4 de marzo de 1803, dentro del término del mandato para el cual habían sido designados. Jorge Alejandro Amaya, Marbury v. Madison. Origen, argumentos y contraargumentos del control judicial de constitucionalidad (5 edición), Astrea, 2017. También destacaron el error los comentarios de Osvaldo Pérez Sanmartino, Un juez que da consejos más que un juez es un amigo, www.endisidencia.com; y Diéguez Jorge A., La Corte Suprema rechazó la acción. La presidenta del Senado consiguió la certeza, Instituto de Derecho Constitucional, de la Academia Nacional de Derecho y Ciencias Sociales de Buenos Aires, documento de trabajo, reunión del 16/06/2020.

7. Jorge Alejandro Amaya, Control de Constitucionalidad (2da. Edición actualizada y ampliada) (1ra. Reimpresión), capítulo III, (Buenos Aires: Astrea 2017). También utiliza esta denominación conceptual Alberto Dalla Vía, Modelos, tribunales y sentencias constitucionales, www.juridicas.unam.mx

8. Es exagerado considerar a Marshall el padre del control judicial y así lo expusimos en nuestro libro Marbury v. Madison. En el mismo sentido ver un documentado trabajo de Manuel García Mansilla, Marbury v. Madison y los mitos acerca del control judicial de constitucionalidad, exposición del autor ante el Instituto de Derecho Constitucional de la Academia Nacional de Derechos y Ciencias Sociales de Buenos Aires, abril de 2020. Ver también Garay Alberto, "La enseñanza del caso Marbury v. Madison”, Revista Academia, sobre enseñanza del Derecho año 7, número 13, (2009), 
nacido a principios del siglo XX por diseño de Hans Kelsen y su recordado debate doctrinario con Carl Schmitt; y el político o francés que reflejó principalmente la constitución gala de 1958, constituyen tres claros ejemplos de lo afirmado.

Definimos como sistemas de control de constitucionalidad a los diseñados por los países, tomando un modelo preexistente; o combinando características de distintos modelos, ya sea por disposición de la propia constitución del país (la enorme mayoría de las naciones europeas y latinoamericanas construyen sus sistemas detalladamente desde la Constitución) (así lo hace también el derecho público provincial); por normas infra-constitucionales (habitualmente reglamentarias); o por construcción fuertemente jurisprudencial (nuestro sistema federal) ${ }^{9}$.

\section{LOS MODELOS, SUS REGLAS, CARACTERÍSTICAS E IDENTIDAD}

El modelo de la judicial review nacido en los Estados Unidos en el siglo XVIII deposita en todos los jueces de cualquier jurisdicción y competencia el ejercicio del control de constitucionalidad de los actos de los poderes políticos del gobierno.

Varios argumentos jurídicos, políticos, e ideológicos, se alinearon para dar nacimiento al modelo. La novedad de una constitución escrita que incluía una cláusula de supremacía ${ }^{10}$; el sistema jurídico de las colonias estadounidenses ${ }^{11}$, los ricos debates de la Convención de Filadelfia ${ }^{12}$, y la enorme influencia

\section{$121-136$}

9. Contrariamente a la enorme mayoría de los países occidentales nuestro sistema de control está regulado por algunas pocas normas constitucionales y reglamentarias abiertas. La mayor parte de sus características y precisiones deviene de creaciones pretorianas de la CSJN.

10. La característica original de la Constitución de los Estados Unidos fue plasmar en una Constitución escrita ese parámetro normativo superior que decide la validez de las leyes del Legislativo, al recoger en su Título VI, la declaración de la supremacía de la Constitución como la ley suprema del país (the supreme law of the land); consecuentemente, gozará de superioridad jurídica (shall enjoy legal superiority) por encima de cualquier disposición opuesta o contradictoria (conflicting provisión) contenida en las leyes o en las Constituciones de los estados de la Unión. Esta previsión se la conoce como "Cláusula de Supremacía" (Supremacy Clause).

11. Un antecedente claro del sistema de control judicial de constitucionalidad de las leyes, lo constituye el sistema jurídico vigente en las colonias norteamericanas. Antes de la independencia de las mismas, las Cartas o Estatutos de la Corona Inglesa permitían que las Colonias se dieran sus propias normas, siempre y cuando no contradijeran a aquéllas, previendo que, en caso de existir contradicción, los jueces no aplicarían la ley norteamericana, dejando clara la supremacía del Parlamento Inglés y de sus normas.

12. El mecanismo de control judicial de constitucionalidad de las leyes no tuvo, como sabemos, una regulación explícita en el texto constitucional. Sin embargo, en ocasión del debate mantenido entre los partidarios y detractores de la inclusión en el texto de la constitución de un Consejo de Revisión propuesto por el Convencional por Pensilvania James Wilson, se producirían intervenciones en que se suscitaría la problemática del control de constitucionalidad de las leyes dictadas por el Congreso Federal y la necesidad de la participación de los jueces en el control. La práctica (judicial o política) tenía ya en los territorios de la futura Unión precedentes jurídicos inmediatos, bien de carácter legal, como los que supusieron los Consejos de Censores que habían creado en su momento las constituciones de Pensilvania y de Vermont o el Consejo de Revisión establecido en la constitución de Nueva York; bien de carácter jurisprudencial, como 
de los fathers fundation ${ }^{13}$, en el marco de sistema jurídico de tradición anglosajona, confluyeron para avalar la confianza en los jueces como custodios de la supremacía constitucional.

El modelo judicial difuso se caracteriza desde su nacimiento por ser un control concreto en el marco de una causa, no en forma directa sino incidental. La cuestión constitucio $\neg$ nal no es objeto principal, pero se presenta como una cues-tión que ha de ser lógicamente deslindada para la solución del litigio concreto.

La declaración de inconstitucionalidad no tiene, por tanto, efectos erga omnes, sino solo entre las partes que dieron origen al pleito. La norma invalidada no pierde vigencia en el firmamento jurídico, solo resulta inaplicable en el caso concreto, el cual está delimitado por el hecho que le dieron origen.

Como consecuencia de su ideología (supuestamente contra-mayoritaria) y características principales (judicial difuso, concreto, incidental, y de efecto inter-partes) el modelo se construyó en base a reglas, definidas como las reglas del control, que se fueron desarrollando pretorianamente y receptando normativamente, y que son conocidas en doctrina como las reglas de Marshall, de Cooley y de Brandeis ${ }^{14}$.

los derivados de pronunciamientos contenidos en las sentencias de los tribunales estatales. Amaya, Jorge Alejandro, op. cit. p. 26/28.

13. La influencia más notoria lo representan The Federalist Papers. Se trata de una serie de ochenta y cinco artículos que abogan por la ratificación de la constitución norteamericana. Los escritos sirven como fuente primaria para la interpretación de la constitución, pues pretenden explicar la filosofía inspiradora de esta y la motivación del sistema de gobierno propuesto. Los artículos fueron escritos por Alexander Hamilton (Números 1, 6-9, 11-13, 15-17, 21-36, 59-61, y 65-85), James Madison (Números 10, 14, 18-20, 37-58, y 62-63) y John Jay (Números 2-5, y 64). A Madison se le considera el padre de la constitución y fue el cuarto Presidente de los Estados Unidos. Hamilton fue un delegado activo en la Convención Constituyente, y se convirtió después en el primer Secretario de Hacienda. Jay, por su parte, se convirtió en Presidente de la Corte Suprema de Justicia. La Corte Suprema de Justicia de los Estados Unidos considera que debe concederse gran peso a la forma como interpretan la constitución los autores de El Federalista (Sentencias McCulloch v. Maryland y Pollock v. Farmer's Loan and Trust Company, citadas en la edición oficial de la Constitución de los Estados Unidos de América, Washington 1938, p. 66).

14. 1) El control es incidental, o sea, nace y se desarrolla en el seno de un proceso judicial. La cuestión constitucional no es objeto principal, pero se presenta como una cuestión que ha de ser lógicamente deslindada para la solución del litigio; 2) Rige la noción de "causa", lo que implica que los jueces solamente pueden pronunciarse dentro de los juicios que se planteen ante sus estrados; 3 ) Los jueces ejercen el control de constitucionalidad en casos concretos y no cuando la cuestión ha devenido abstracta; 4) Los jueces ejercen el control de constitucionalidad a pedido de las partes interesadas y que tengan un interés concreto en la no aplicación de la norma pretendidamente inconstitucional (standing); 5) Los tribunales judiciales no ejercen control sobre las cuestiones no justiciables, políticas o actos de gobierno (según lo que ellos mismos han ido calificando como tales); 6) Los jueces se pronuncian sobre la constitucionalidad o inconstitucionalidad de las normas impugnadas en las sentencias, produciendo efectos que, en principio, se circunscriben al caso concreto, pero que en varios otros tienen un alcance más genérico, en virtud de la regla del precedente; 7) La resolución judicial acerca de la constitucionalidad de una norma o de su inconstitucionalidad sólo afecta a las partes (efecto inter partes) y los efectos de la declaración en cuestión no se extienden al resto de la norma, que mantiene vigencia en el ordenamiento; 8) La sentencia es declarativa, porque el pronunciamiento de inconstitucionalidad opera como declaración de certeza retroactiva de una "nulidad" preexistente y, por tanto, con efectos ex tunc; 9) la inconstitucionalidad es la última ratio, es decir que no debe la judicatura declarar la inconstitucionalidad a no ser que sea absolutamente necesario; 
Contrariamente, el modelo concentrado tuvo su primera expresión en la Constitución Checoslovaca del 29 de febrero de 1920, más de un siglo después del modelo judicial difuso, adelantándose a la Constitución Austríaca de octubre de 1920, célebre por la influencia de Kelsen.

Si bien el modelo concentrado austríaco presenta diferentes momentos, la consagración de un sistema de justicia constitucional autónoma y concentrada en un único tribunal; un Tribunal Constitucional que controla de manera concentrada y abstracta la constitucionalidad de las leyes se materializó en el art. 140 de la Constitución austríaca de 1920, incorporándose también la actuación de oficio ${ }^{15}$.

El nuevo modelo introduce un cambio básico respecto del modelo judicial estadounidense, concentrando dicho control en un solo Tribunal por fuera de la justicia ordinaria, y consagrándose un modelo de características concentradas, especializado, de control fundamentalmente abstracto, y efectos erga omnes; muy diferente al difuso, judicial, concreto y de efecto inter partes de los norteamericanos.

Kelsen al defenderse de la objeción que se formula a su modelo cuando se le imputa que atenta contra el principio de separación de poderes, responderá que el Tribunal Constitucional no es un verdadero tribunal, sino un legislador negativo. Dirá que el órgano al que está encomendada la anula $c$ ción de las

10) si existe un fundamento en la causa que permita que la cuestión constitucional pierda relevancia, los jueces deben adoptar dicho camino; 11) la cuestión constitucional sólo puede ser invocada por quien alegue y pruebe un perjuicio; 12) la duda sobre la constitucionalidad de una ley no es causa suficiente para su declaración; los jueces no pueden declarar la inconstitucionalidad en procedimientos que no sean contenciosos, es decir voluntarios o donde no existan partes encontradas; 13) no se puede anticipar una decisión de inconstitucionalidad a la necesidad de decidirla; 14) no se puede formular una regla de constitucionalidad más amplia que la requerida por los hechos a los cuales ha de aplicarse; 15) si el caso puede resolverse apelando a una solución legal sin involucrar una cuestión constitucional, debe optarse por esta solución; 16) no puede analizarse la constitucionalidad de una ley a instancia de una parte que no ha podido probar que su aplicación le ocasiona perjuicios; 17) no se puede declarar la inconstitucionalidad de una ley a instancia de una parte que se ha beneficiado con ella; 18) las leyes siempre deben ser interpretadas evitando, en lo posible, su declaración de inconstitucionalidad.

15. El sistema concentrado de jurisdicción constitucional establecido en la Constitución austríaca de 1920 sufrió moาdificaciones debido a dos reformas importantes en 1925 y 1930. La reforma de 1925 es de carácter predominantemente técnico. Prevé una "consulta previa de competencia", tanto por parte de la federación como de los Lander, ante el Triาbunal Constitucional, acerca de la titularidad de una com $\neg$ petencia determinada. Por su parte, la reforma constitucional de 1929, en re $\neg$ lación con el control de constitucionalidad, es tanto de ca $\neg$ rácter técnico como de carácter político. En el primer caso, se introdujo de manera restringida lo que se llamará "con $\neg$ trol concreto", propuesto por KELSEN. La modificación de carácter político se presentó con el propósito de disminuir el ascendiente de los partidos polítiาcos en la composición del tribunal. El nuevo art. 147 constitucionalizó el número de los magistrados y suplentes, y debilitó decididamente la intervención de las cámaras en el nombramiento de aquéllos, reforzando con la misma inten $\neg$ sidad la intervención del gobierno federal. Es evidente que con esta modificación lo único que se obtuvo es el desequi $\neg$ librio del Tribunal Constitucional, a favor del partido go-bernante. Otro elemento que contribuyó a debilitar la inde $\neg$ pendencia de los miembros del tribunal fue la sustitución de su carácter vitalicio por el principio general de jubila $\neg$ ción de los miembros del Poder Judicial, con la llegada de la edad reglamentaria. La ley de transición que acompañó la reforma dispuso el cese de todos los miembros del tribunal con fecha de 15 de febrero de 1930. De este modo se ocasionó una ruptura en su composición. Amaya, Jorge Alejandro, Control de Constitucionalidad (2da. Edición actualizada y ampliada, $1^{\text {a }}$ reimpresión), (Buenos Aires: Astrea, 2017). 
leyes inconstitucionales, aunque reciba por la independencia de sus miembros- la organización propia de un tribunal, no ejerce sin embargo verdaderamente una función jurisdiccional.

En la medida en que se puede distinguir entre ellas, la diferencia entre la función jurisdiccional y la función legislativa reside ante todo en que ésta crea normas generales, mientras que aquélla sólo crea normas individuales. Anular una ley es dictar una norma general; porque la anulación de una ley tiene el mis $\neg$ mo carácter de generalidad que su producción y no es, por así decirlo, sino producción con un signo negativo y, por tanto, una función legislativa.

En la parte final de su trabajo, y bajo el título de La significación jurídica y política de la justicia constitucional, Kelsen resalta la importancia de la garantía de la anulabilidad de los actos inconstitucionales, si se quiere afirmar jurídicamente la supremacía de la constitución. Afirma que una constitución que carezca de la garantía de la anulabilidad de los actos inconstitucionales no es una constitución plenamente obligatoria en sentido técnico ${ }^{16}$.

Los sistemas constitucionales contemporáneos han alumbrado otras soluciones a los modelos norteamericano y kelseniano, los cuales si bien pueden encuadrarse en último término en la dicotomía clásica control jurisdiccional-control político, algunos de ellos poseen rasgos propios y originales, tal el caso del control francés que consideramos un auténtico modelo.

Históricamente América y Europa -y dentro de ésta principalmente Francia- transitaron por distintas orientaciones, producto de los acontecimientos disímiles de sus respectivas revoluciones. Mientras en América del Norte el parlamento inglés aparecía como el gran opresor, siguiéndolo el rey y su gobierno y los tribunales se erigían como defensores de la libertad, en Francia sucedía lo contrario.

Las monarquías absolutistas y la judicatura, como brazo ejecutor de los deseos del rey, tenían que ser limitados por la legislatura, sede de la representación popular más genuina. La doctrina de Rousseau sobre la inefabilidad del Legislativo, que se conecta con la expresión de la ley como voluntad general, incidirá decisivamente en el modelo francés.

El constitucionalismo primitivo francés descansará en la confianza absoluta en el legislador, asumiendo una posición de recelo hacia el juez, servidor del príncipe en el Estado absoluto. Los argumentos precedentes llevaron a Europa, y principalmente a Francia, a hablar del gobierno de los jueces para describir al modelo estadounidense, señalando de ese modo el carácter no representativo del sistema ${ }^{17}$.

La constitución de la Quinta República francesa de 1958, inició un nuevo sesgo en el control de constitucionalidad de las leyes con la creación del Consejo Constitucional. ¿¿Se asemeja el Consejo Constitucional francés a los tribunales constitucionales imperantes en el resto de los países? Si bien el

16. Kelsen "La garantía jurisdiccional de la Constitución (la justicia constitucional)", Revista Iberoamericana de Derecho Procesal Constitucional, $\mathrm{n}^{\circ} 10,3$.

17. Pedro Nestor Sagués. Recurso extraordinario, T 1, Vol. 2, (Buenos Aires, Argentina: Editorial Astrea, 2002). 
Consejo se aproxima muchos más a ellos que a la función de la Corte Suprema estadounidense, mantiene un perfil y características particulares pues su creación no responde a los mismos objetivos.

La atribución a él de un control preventivo y preceptivo sobre las leyes orgánicas y los reglamentos de las asambleas parlamentarias se orienta a frenar el excesivo poder que la Asamblea Nacional tuvo en el período de 1946 a 1958.

La función no está limitada al único ámbito de la normatividad, dado que ha sido investido de competencias más amplias, que se conectan directamente con las relaciones entre los poderes públicos. Más allá de la amplitud de competencias, el debate se centró en si sus funciones eran jurisdiccionales o políticas y ambas tesis fueron defendidas con buenos argumentos ${ }^{18}$.

Parecería que el modelo francés diseñado por la Constitución de 1958 es un modelo intermedio entre los modelos jurisdiccionales y los políticos, con mayor inclinación por las características de estos últimos ${ }^{19}$.

Los modelos de control que muy someramente hemos descripto ${ }^{20}$ se sustentan en identidades diferentes.

Como poderes del Estado la Corte Suprema y los Tribunales Constitucionales por medio de sus fallos no sólo deciden, también gobiernan, entendiéndose por ello la fijación de políticas que emanan de la interpretación, aplicación, invalidación o validación de los múltiples actos de gobierno mediante el ejercicio del control de constitucionalidad. Desde esta perspectiva, las identidades originarias de los dos grandes modelos del control ${ }^{21}$ nacieron con dos perfiles dispares.

Una identidad contra-mayoritaria se le asigno al judicial difuso (sosteniendo que su principal misión era el control del poder político frente a los derechos individuales y las minorías) ${ }^{22}$; y una identidad

18. Para una defensa de la tesis jurisdiccional puede verse. Martín Retortillo, "Consideraciones sobre los tribunales constitucionales (El supuesto del Consejo Constitucional francés)", Revista Española de Derecho Administrativo, $\mathrm{n}^{\circ}$ 15, 562. La tesis política es sostenida, entre otros, por, Henry J. Abraham The judicial process, séptima edición, (Oxford University Press, mayo 1998), 263.

19. El 23 de julio de 2008 se sancionó la ley constitucional 724 que modificó de manera trascendente la constitución francesa de 1958. En lo que respecta al Consejo Constitucional se produjeron im-portantes cambios, al ampliarse la función preventiva clásica en el control de constitucionalidad hacia la posibilidad que el Consejo Constitucional intervenga a efectos de controlar la constitucionalidad de una norma, cuando en el trámite de un proceso judicial se la cuestiona. En este caso, el Consejo de Estado o la Cámara de Casación pueden enviar al Consejo Constitucional la cuestión para su tratamiento. De esta manera, el sistema se asemeja al español, al combinar el control preventivo y el posterior, acercándose el modelo francés al modelo kelseniano que rige en la mayoría de los países de Europa.

20. Puede ampliarse este tema en nuestra obra Control de Constitucionalidad (2da. Edición actualizada y ampliada, $1^{\mathrm{a}}$ reimpresión), Capítulo III, (Buenos Aires: Astrea, 2017).

21. Sin duda el judicial difuso y el modelo de Tribunal Constitucional son los que atrajeron el mayor interés en Europa y Latinoamérica.

22. Los ideólogos de la Constitución de los Estados Unidos de América justificaron plenamente el control judicial de las 
de garante del proceso democrático se les atribuyó a los Tribunales Constitucionales, cuya principal función transitaba por preservar las reglas del proceso democrático y abstenerse de participar en la reglamentación de los derechos, reservada al Legislativo.

El Tribunal Constitucional aparecía en el pensamiento de Kelsen como complemento del Poder Legislativo, y más respetuoso de las credenciales democráticas del Parlamento ${ }^{23}$.

Planteadas así las opciones, el modelo estadounidense o judicial tuvo por misión sujetar a las mayorías coyunturales -reflejadas en el poder público- a la supremacía constitucional en bien de preservar los derechos constitucionales de las minorías, y el kelseniano buscó, en cambio, diseñar un sistema de revisión constitucional que no fuera hostil con las legislaturas, sino - muy por el contrario- que fuera complementario de la función de éstas.

\section{LA CONVERGENCIA DE LOS MODELOS}

El fenómeno de la justicia constitucional tras la Segunda Guerra Mundial produ-ce un impacto notable en todo el mundo, no sólo por la aparición del modelo de Tribunal Constitucional que acaparó el interés de casi todos los países europeos y de muchos de América Latina unos años después, sino que ha acentuado un proceso recíproco de incorporación de elementos pertenecientes a los dos modelos más aceptados de control de constitucionalidad de normas, hasta el punto de llevar a decir a Rubio Llorente, que hablar actualmente de un sistema europeo carece de sentido, porque hay más diferencias entre los sistemas de justicia constitucional existentes en Europa que entre alguno de ellos y el estadounidense ${ }^{24}$.

Conviene precisar en qué consistió ese proceso de convergencia entre los referidos modelos. De acuerdo con los postulados teóricos de KELSEN, la función del Tribunal Constitucional no es una función propiamente jurisdiccional, sino -de manera más adecuada- legislativa.

Así, al acentuar el carácter político de la función desempeñada por el tribunal, el jurista austríaco trataba de justificar el otorgamiento de efectos erga omnes a la sentencia y la exclusión de la fuerza retroactiva propia de una sentencia judicial.

leyes. Desconfiaban profundamente de la capacidad del pueblo para actuar colectivamente y asumieron que las asambleas legislativas eran propensas a guiarse más por impulsos repentinos que por la razón. Bajo el influjo de esas premisas Hamilton concibió a la revisión judicial como un remedio destinado a refrenar esos arrebatos irracionales. Uno de los objetivos del Poder Judicial en el ejercicio del control de constitucionalidad era, justamente, la preservación de las minorías frente al posicionamiento mayoritario del gobierno de turno.

23. Kelsen, "La garantía jurisdiccional de la Constitución (la justicia constitucional)", Revista Iberoamericana de Derecho Procesal Constitucional, $\mathrm{n}^{\circ} 10,3$ a 46.

24. Rubio Llorente, “Tendencias actuales de la jurisdicción constitucional en Europa”, en Manuel Fraga. Homenaje académico, vol. II, 1411 y 1416. 
Esta concepción del legislador negativo sería relativizada por el propio Kelsen al admitir que la mayor garantía al sistema de control consistía en la previsión de una acción popular, más allá de no considerarla recomendable por razones prácticas.

La reforma a la Constitución austríaca de 1929 va a acoger una primera apertura en este sentido, introduciendo en el art. 140.1 la legitimación al Tribunal Supremo y al Tribunal de Justicia Administrativa para plantear lo que ahora se conoce como una cuestión de inconstitucionalidad, iniciando el camino de aproximación entre el control de constitucionalidad concentrado y el control difuso, que de-sembocó en el denominado sistema mixto.

Esa flexibilización se va a reforzar en Austria con la reforma de 1975, que amplió la legitimación para el planteamiento de la cuestión de inconstitucionalidad a todos los órganos de la jurisdicción común, rasgo que, conectado al procedimiento -según el propio Kelsen- constituía la maᄀyor diferencia con el sistema estadounidense, en donde sólo la violación del interés de un particular podía desencadenar el procedimiento de control constitucional, lo que significa $\neg$ ba la postergación del interés público que el control de constitucionalidad de las leyes entraña, y que no necesariamente coincide con el interés privado de las partes interesadas ${ }^{25}$.

Por otra parte, tras la Segunda Guerra Mundial, la enérgica toma de posición de los Tribunales Constitucionales en el sentido de precaverse frente a una hipotética legislación arbitraria y vulneradora de los derechos fundamentales, llevaría a una concepción de la constitución muy próxima a la estadounidense, como higher law o ley superior.

Esas premisas de la concepción de la constitución como ley superior, el carácter limitado de los poderes constituidos, expuestas por Hamilton en El Federalista, y que Marshall tomaría como punto central de apoyo de su célebre sentencia, al reafirmar el mecanismo difuso de control de la constitucionalidad de las leyes, es la base sobre la que Alemania e Italia van a erigir su sistema. Según García de Enterría "el sistema adoptado en Alemania y en Italia va a ser el norteamericano de la supremacía constitucional junto con algunos rasgos del otro sistema en cuanto instrumento técnico, tesis hoy ya común, sobre todo en la doctrina alemana" 26 .

Por otro lado, si al carácter normativo de la constitución se anuda el hecho que los jueces y tribunales en Europa deben aplicar la ley que se acomode a la constitución, se advierte que ellos también desempeñan una parte considerable del control de constitucionalidad y, en esa medida, buena parte del control antes concentrado se torna difuso y concreto.

25. Fernández Segado, "La obsolescencia de la bipolaridad 'modelo americano-modelo europeo-kelseniano' " como criterio analítico del control de constitucionalidad y la búsqueda de una nueva tipología explicativa”, Parlamento y Constitución, (2002), 30.

26. García de Enterría, El alcance del control judicial de las administraciones públicas en los Estados Unidos de América, 134. 
Pero el dato más significativo en el quebrantamiento de la concepción kelseniana del legislador negativo, es el papel francamente creativo que los tribunales constitucionales pasan a desempeñar cuando asumen, como intérpretes y supremos guardianes de la constitución funciones propias de un legislador positivo por medio de principios y técnicas sofisticadas de interpretación que han originado una tipología de sentencias llamadas interpretativas, un género de variantes especiales, hasta las más extremas llamadas sentencias manipuladoras de diversificado alcance, las cuales operan positivamente, modificando e innovando el ordenamiento con la introducción de normas nuevas o diferentes de las expresadas en el texto enjuiciado ${ }^{27}$.

Europa sigue, desde la segunda mitad del siglo XX -en buena parte como consecuencia de un conjunto de exigencias derivadas del Estado social y democrático de derecho, una evolución a grandes rasgos semejante, no obstante sus características propias, a la seguida por el derecho constitucional estadounidense.

También allí hay constitución viviente (living Constitution), necesitada, como en los Estados Unidos de América, de una permanente actualización por parte de la jurisprudencia constitucional; reconocimiento de que en la interpretación constitucional hay un inevitable elemento de creación de derecho (law making); y que el control jurisdiccional de las leyes no puede ser realizado únicamente a partir de criterios formales de hermenéutica jurídica.

Así, aun cuando los sistemas de justicia constitucional hubiesen sido creados con miras a causar distintos efectos, la experiencia indica que los dos grandes modelos han desembocado en una práctica muy parecida, es decir se han acercado en los efectos de sus diseños originales.

En primer lugar no es cierto que los Tribunales Constitucionales hayan ejercido sólo como legisladores negativos. En muchas ocasiones, ellos no limitan su tarea a la anulación de leyes inconstitucionales, sino que además fijan las interpretaciones constitucionales. En muchos países, asimismo, están autorizados a declarar la inconstitucionalidad de las omisiones legislativas (ejemplo, el Tribunal Constitucional de Portugal).

Las constituciones europeas no se limitan a regular procedimientos y competencias, sino que consagran además un conjunto de principios abstractos y derechos que también vinculan al juez constitucional. Este vínculo del juez con los derechos tiene lugar fundamentalmente por medio de la acción de amparo (tutela o protección) o de la cuestión de constitucionalidad que plantean los jueces ordinarios.

Además, la consideración de cuestiones fácticas no tiene lugar sólo cuando la Corte revisa sentencias de amparo, sino también cuando ejerce el control de constitucionalidad de las leyes. Ello debido

27. Néstor Pedro Sagüés, "Las sentencias constitucionales exhortativas". Estudios Constitucionales, vol. 4, n 2 , Centro de Estudios Constitucionales de Chile, (2006),189 a 202. 
a que -en contra de lo imaginado por KELSEN- actualmente se reconoce que este control no puede limitarse a ser un juicio de compatibilidad lógica entre dos normas, en el que sólo intervienen premisas normativas. Ello no es posible, por ejemplo, en los casos difíciles que plantean colisiones entre principios jurídicos.

A su vez, figuras como el amparo judicial o la cuestión de inconstitucionalidad, en el sistema español por ejemplo, desvanecen el dualismo sentado por el modelo kelseniano entre la justicia ordinaria y la constitucional.

Esto es así porque en tanto que algunos jueces ordinarios conocen de las acciones de amparo, éstos pueden imprimir a las leyes una interpretación contraria al significado dado por el legislador. Esta posibilidad debilita el monopolio del Tribunal Constitucional para aplicar directamente contenidos constitucionales (aun cuando, naturalmente, los jueces ordinarios siguen sin contar con la potestad de declarar la invalidez de una ley).

También los efectos de las sentencias del Tribunal Constitucional no siempre son ex nunc (para el futuro). En general, se reconoce a los Tribunales Constitucionales la potestad de modular los efectos temporales de las sentencias. Por ejemplo, cuando el juez considera que existe un vicio grave y manifiesto, la sentencia produce efectos ex tunc (es decir, tiene efectos retroactivos)

Algunos rasgos del modelo estadounidense tienden a asemejarse con el europeo. Así, no es del todo exacto que en el modelo estadounidense las sentencias de inconstitucionalidad posean efectos sólo para el caso concreto. Por el principio del stare decisis, por medio del cual las doctrinas jurisprudenciales de la Corte Suprema resultan obligatorias, los efectos singulares de las sentencias se propagan a otros casos análogos que se ventilan ante los tribunales inferiores. Aunque ello todavía no sea idéntico a la derogación general de una ley, lo cierto es que los efectos de la sentencia trascienden el caso concreto $^{28}$.

Incluso respecto de sus identidades de origen, también se ha producido un acercamiento en los modelos, ya que los Tribunales Constitucionales han terminado practicando una conducta bastante hostil hacia el Poder Legislativo ${ }^{29}$; y las Cortes Supremas (al estilo norteamericano como la Argentina) se situaron en posición de deferencia hacia los actos de los poderes políticos del Gobierno, como sucede en el caso que comentamos en este trabajo. Esto es muy notorio, a nuestro modo de ver, en la jurisprudencia de la CSJN de los últimos ochenta años (con algunos periodos excepcionales).

28. Para ampliar este tema puede verse Sebastián Linares, La (i) legitimidad democrática del control judicial de las leyes, Marcial Pons, (Madrid: 2008).

29. Dentro de quienes argumentan la inversión de la identidad de los tribunales constitucionales se encuentra Ferreres Comella. Según su tesis, los Tribunales Constitucionales europeos propician actualmente una conducta activista en contra del Legislativo y en especial en contra del Legislativo de turno. Ver la obra del autor, Justicia Constitucional y Democracia, (Madrid: Centro de Estudios Políticos y Constitucionales, 1997). 


\section{LOS SISTEMAS LATINOAMERICANOS. SISTEMAS MIXTOS}

Los sistemas latinoamericanos de control de constitucionalidad han combinado características de los tres modelos descriptos en el punto III., por ello se denominan mixtos, con independencia de cuál modelo prevalezca en el sistema de cada país. La justicia constitucional desarrollada en América Latina es una de las más variadas del mundo.

El modelo concentrado de control de constitucionalidad se hace presente en muchos sistemas latinoamericanos. Algunos países, lo han adoptado en forma exclusiva, atribuyendo la justicia constitucional sólo a la Corte Suprema de Justicia, como en el caso de Panamá, Uruguay y Honduras; o a una Sala dentro de la Corte Suprema, como los casos de Paraguay y Costa Rica. Normalmente, en estos supuestos, el control se puede ejercer por vía de acción popular o por el legitimado directo, o en virtud de una incidencia en el proceso que se eleva en consulta a la Corte Suprema, que puede ser activada por las partes o de oficio por el juez.

En algunos sistemas exclusivamente concentrados de control de constitucionalidad de las leyes, las decisiones de las Cortes Supremas sólo tienen efectos inter partes (Uruguay, Paraguay, Honduras), con excepción de Panamá, donde los efectos de las sentencias son erga omnes.

En otros sistemas el modelo concentrado se combina con el modelo difuso. Aquí la jurisdicción constitucional es compartida por todos los jueces de manera difusa y por la Corte Suprema o el Tribunal Constitucional de modo concentrado (dependiendo de qué organización judicial impere) a los cuales se accede directamente por acción popular o por legitimados específicos, los cuales son normalmente funcionarios públicos.

En general, en la mayoría de los países en los cuales se ha establecido el sistema de control concentrado combinado con el difuso, los efectos de las decisiones de los máximos tribunales son anulatorios erga omnes; por tanto, de carácter constitutivo y de valor ex nunc, pro futuro (Venezuela, México, Brasil, Perú, Colombia, Guatemala, Bolivia, Ecuador).

En algunos países se permite darle efectos retroactivos a las decisiones anulatorias cuando se trata de algunas materias (penal, fiscal, laboral, etc.); excepcionalmente se establecen los efectos generales ex tunc pro preterito de las sentencias anulatorias de la Corte Suprema, como el caso de Costa Rica.

Cinco países han instituido Tribunales o Cortes Constitucionales fuera de la órbita del Poder Judicial. Ellos son Perú (1979), Chile (1980), Guatemala (1985), Bolivia (1994) y Ecuador (1996 y 1998). Colombia instituyó una Corte Constitucional dentro del Poder Judicial (1991). Otros países, en cambio, han instituido Salas Constitucionales dentro de las Cortes Supremas, con potestades para declarar la inconstitucionalidad de las leyes con efectos generales (Costa Rica (1989), El Salvador (1991), Nicaragua (1995), Venezuela (1999). 
Según parece, el régimen de la Sala Constitucional ha sido una solución política transaccional entre quienes querían, como aspiración de máxima un Tribunal Constitucional extra-poder, y quienes temían que ello restara peso institucional a la Corte Suprema y al Poder Judicial. En cierta medida, la Sala viene a ser una especie de Tribunal Constitucional dentro de la Corte Suprema, pero que de hecho en algunos temas -como los constitucionales- tiende a ser superior a la misma Corte (el caso más llamativo ha sido el de Venezuela, donde su Sala Constitucional entiende que puede revisar en su materia las sentencias de las otras salas del Tribunal Supremo de Justicia).

De los países que no instituyeron Tribunales o Salas Constitucionales, cuatro de ellos han atribuido al pleno de la Corte o Tribunal Supremo la potestad de declarar la inconstitucionalidad de las leyes con efectos generales. Ellos son Brasil (1988), México (1994), Panamá (1982) y República Dominicana (1994).

Sólo Argentina, Uruguay, y Paraguay conservan con carácter exclusivo- un control de constitucionalidad con efectos únicamente para el caso concreto (en el caso de Uruguay y Paraguay el control es concentrado, en Argentina difuso).

Por otra parte, la gran mayoría de los países han instituido acciones abstractas de inconstitucionalidad. En esa línea, resulta curioso observar que ocho países acogen alguna especie de acción popular, un mecanismo de acceso a la justicia constitucional que no tiene grandes adeptos en Europa (salvo en Hungría) pero que según parece concita el mismo activismo que las acciones orgánicas (Colombia, Guatemala, El Salvador, Nicaragua, Panamá, República Dominicana, Venezuela y aunque con importantes limitaciones- Costa Rica).

Trece países reconocen acciones orgánicas de inconstitucionalidad, es decir, acciones que pueden ser planteadas sólo por funcionarios u organismos políticos ante la Corte Suprema, Sala Constitucional o Corte de Constitucionalidad. En siete de ellos la acción orgánica convive con la acción popular (Colombia, Guatemala, El Salvador, Panamá, República Dominicana, Venezuela y Costa Rica). En los otros seis países, la acción orgánica es de carácter exclusivo (es decir, no hay otro mecanismo alternativo para acudir directamente ante el TC o Corte); ellos son Bolivia, Brasil, Chile, Ecuador, México y Perú, todos bajo distintas modalidades específicas.

Cabe inferir, como rasgo notable de esta clase de acciones, que -salvo los casos de Guatemala, México y El Salvador- todos los demás países atribuyen esta clase de acción al Presidente de la República (de manera exclusiva o junto con la legitimación de otros órganos). Ello encuentra justificación, de algún modo en la naturaleza presidencialista de los regímenes políticos latinoamericanos.

Por su parte, Honduras, Paraguay y Uruguay reconocen una acción de inconstitucionalidad que puede ser planteada ante el órgano constitucional por cualquier persona que demuestre un agravio o interés legítimo, sin necesidad de agotar todas las instancias judiciales. 
Seguidamente tenemos la cuestión de inconstitucionalidad. Por este cauce, si un juez ordinario estima que la ley aplicable al caso que debe resolver es (o puede ser) inconstitucional, debe suspender el procedimiento antes de dictar sentencia y elevar la cuestión ante el órgano constitucional. Éste decidirá si la ley es o no válida, para que luego el juez ordinario pueda finalmente resolver el caso concreto. Hay que decir también, que la cuestión de constitucionalidad puede ser planteada de oficio o a petición de parte. En el último caso, esta solicitud puede tener carácter vinculante o no (es decir el juez ordinario puede estar obligado o bien tener discreción para presentar la cuestión de constitucionalidad). Recogen alguna clase de cuestión de constitucionalidad Costa Rica, Honduras, Panamá, Paraguay y Uruguay.

Como vemos, todos los países latinoamericanos presentan rasgos propios del modelo europeo. Crean un Tribunal Constitucional; consagran la declaración general de inconstitucionalidad en la figura de las Salas Constitucionales o en la Corte Suprema; o reconocen alguna especie de acción de inconstitucionalidad que activa un control de tipo concentrado; o admiten -aunque sea- un control de carácter concentrado (Uruguay).

El Tribunal Constitucional Chileno, se presenta como el más europeo de los seis Tribunales Constitucionales Latinoamericanos, pues no sólo conoce de la acción abstracta que pueden ejercer algunos funcionarios políticos, sino que prescinde de conocer de las acciones de amparo, o de conocer cualquier otro tipo de recurso ordinario.

En el otro extremo está (o estaba) el sistema argentino, que pese a las reformas constitucionales de 1994- todavía sigue ostentando un modelo próximo al estadounidense. No sólo carece de la declaración general de inconstitucionalidad, sino que recoge instituciones análogas a las del writ of certiorari, que le permiten adoptar abiertamente y sin justificación una estrategia de evitación de las cuestiones de constitucionalidad.

\section{LOS SISTEMAS PROVINCIALES ARGENTINOS. SISTEMAS MIXTOS}

Conforme a las características del Estado Federal argentino, las provincias organizan su propio sistema de control de constitucionalidad dentro de la jurisdicción local en la medida en que el conflicto se circunscriba a la tensión entre normas locales y la Constitución Provincial, pudiendo intervenir la CSJN solo cuando se encuentre en juego una cuestión federal simple o compleja ${ }^{30}$.

Así como en el ámbito Federal, la República Argentina es el país latinoamericano que ha sostenido de manera más fiel el modelo estadounidense, a nivel estadual los sistemas locales en la mayoría de los casos evidencian características del modelo concentrado, constituyendo sistemas mixtos de control.

Efectivamente, la mayoría de los estados provinciales combinan el control difuso con un control concentrado de carácter preventivo que se ejerce habitualmente por acciones de inconstitucionalidad

30. Fallos, 301:615, y 301:624. 
planteadas en competencia originaria y exclusiva de los Superiores Tribunales de Justicia, actuando así los Altos Tribunales provinciales por vía de recurso de apelación y por vía de acción ${ }^{31}$.

Inicialmente consagraron la acción de inconstitucionalidad las constituciones de las provincias de Neuquén (1957) (arts. 30, 167, 170 inc. a, y 171 inc. a); Chaco (1957) (arts. 9º y 170); Río Negro (1957) (arts. 137 y 138); Misiones (1958) (arts.145, inc. 1); y La Pampa (1960) (arts. 7º, 97 y 101).

Durante la primera ola de reformas a las constituciones provinciales, es decir, las reformas producidas entre 1983 y 1994, fecha en que se modificó la Constitución nacional, consagraron el instituto La Rioja (arts. $9^{\circ}$, 132, 141, 143 y 145); San Juan (arts. 11, 208, 209 y 265); Jujuy (arts. 164 y 165); Salta (arts. 92 y 153); Córdoba (art. 165); San Luis (arts. 10, 210, 213, 214 y 237), y Tierra del Fuego (arts. 54, 157 a 159). Todas estas Provincias dispusieron que la acción directa de inconstitucionalidad se radicara en competencia originaria y exclusiva del Superior Tribunal de Justicia.

Finalmente, durante el segundo ciclo de reformas provinciales, se sumaron las provincias de Buenos Aires (arts. 57 y 161); Chubut (arts. 175 y 179); la Ciudad Autónoma de Buenos Aires (art. 113), y Santiago del Estero, quienes también regularon constitucionalmente el instituto, asignando al Superior Tribunal la com-petencia originaria y exclusiva de esta acción.

Las provincias de Tucumán, Entre Ríos y Mendoza no han previsto de manera expresa, en sus constituciones la acción de inconstitucionalidad, pero la han establecido mediante leyes especiales o en su Código Procesal, sea como atribución exclusiva del Tribunal Superior de Justicia (Entre Ríos) o a cargo de los jueces de primera instancia (Tucumán y Mendoza) (Tucumán lo hace a través de su Código Procesal Constitucional).

Corrientes, Santa Fe, Santa Cruz y Catamarca (al igual que la Nación) no tienen reconocida la acción de inconstitucionalidad en sus constituciones ni en su legislación procesal. Esto no significa que en dichas jurisdicciones no exista la posibilidad de interponer una acción de inconstitucionalidad, la que podrá canalizarse como una acción meramente declarativa contemplada en sus respectivos códigos procesales locales, que reproducen una cláusula análoga al art. 322 del Código Procesal Civil y Comercial de la Nación.

Ahora bien, varias constituciones provinciales se ocupan del efecto expansivo (erga omnes) de las sentencias dictadas en este marco. Neuquén; la Ciudad Autónoma de Buenos Aires; y Santiago del Estero sólo confieren efecto general a aquellas sentencias de inconstitucionalidad dictadas por el Tribunal Superior en los casos de acciones de inconstitucionalidad entabladas directamente ante dicho tribunal. En los casos en los que el Tribunal Superior resuelve por vía de apelación (acción ordinaria, amparo, hábeas corpus, acción meramente declarativa iniciadas ante juez de primera instancia) tales sentencias carecen de efectos expansivos y siguen la regla general del efecto inter partes.

31. La provincia de Buenos Aires fue pionera en establecer, mediante una ley, una acción declarativa de inconstitucionalidad, introducida en su Código de Procedimiento en lo Civil y Comercial de 1906 (ley 2958), aunque no contaba con una cláusula en su Constitución sobre el particular. 
Formosa, La Rioja, San Juan, Río Negro, Tierra del Fuego, Chubut y Jujuy atribuyen alcance general, con distinta intensidad, a cualquier sentencia de inconstitucionalidad dictada por el Tribunal Superior sea que haya conocido por vía directa de una acción de inconstitucionalidad o por vía de apelación en cualquier proceso iniciado ante un juez de primera instancia donde se planteó incidentalmente una cuestión constitucional.

Formosa, La Rioja y San Juan confieren valor de interpretación obligatoria para los tribunales inferiores la sentencia de inconstitucionalidad dictada por el Tribunal Superior de Justicia, característica propia de los sistemas concentrados y del stare decisis norteamericano.

Las provincias de Río Negro, Tierra del Fuego y Chubut exigen el dictado de dos o tres sentencias análogas por el Tribunal Superior de Justicia para llegar a afectar la vigencia de la norma legal tachada de inconstitucional ${ }^{32}$.

Chubut establece que la norma tachada de inconstitucionalidad deja de tener vigencia al día siguiente de su publicación oficial, siendo la primera provincia en otorgar efecto derogatorio propio de un Tribunal Constitucional a las sentencias de inconstitucionalidad pronunciadas por el máximo tribunal local. Exige que haya dos pronunciamientos consecutivos o tres alternados del Tribunal Superior.

Algunas constituciones, cuando la norma impugnada es una ley mantienen un acto de deferencia hacia el Poder Legislativo. Así, Río Negro condiciona la pérdida de vigencia de la ley a que el Tribunal Superior comunique a la Legislatura las tres sentencias unánimes. La Legislatura dispone de seis meses para derogar o modificar la norma inconstitucional. Pasado este término la sanción se agrava, pues se habla directamente de derogación ${ }^{33}$.

Lo mismo sucede con la Constitución de la Ciudad Autónoma de Buenos Aires, que establece que cuando la norma declarada inconstitucional por el Tribunal Superior es una ley el efecto expansivo se suspende por tres meses; dentro de dicho plazo la Legislatura puede ratificar el valor general de la norma. Por tanto, en caso de ratificación legislativa expresa, ésta ópera reduciendo el efecto derogatorio de la sentencia al caso concreto, impidiendo que la norma legal pierda vigencia (anula el efecto expansivo de la decisión judicial).

32. Díaz Ricci, "Panorama y evolución del control de constitucionalidad en los Estados provinciales de Argentina”, Revista Iberoamericana de Derecho Procesal Constitucional, n 11, México: Editorial Porrúa, (2009),184.

33. El art. $9^{\circ}$ de la Constitución del Chaco dispone la "caducidad" de la norma declarada inconstitucional ("La inconstitucionalidad declarada por el Superior Tribunal de Justicia produce la caducidad de la ley, ordenanza o disposición en la parte afectada por aquella declaración"). 
En Neuquén ${ }^{34}$, la Ciudad Autónoma de Buenos Aires ${ }^{35}$ y la provincia de Santiago del Estero, se atribuye el efecto expansivo sólo a las sentencias de inconstitucionalidad pronunciadas por el Tribunal Superior en el marco de las acciones de inconstitucionalidad, dado que en las recaídas en grado de apela-ción en cualquier otro proceso sólo tienen efecto inter partes.

La acción de inconstitucionalidad permite al Superior Tribunal un control abstracto por ejemplo en la Ciudad Autónoma de Buenos Aires (art. 113, 2); Chaco (art. 163, 1º); Neuquén (art. 170. A, 136, y 30); y Río Negro (art. 207, 10).

\section{EL SISTEMA FEDERAL ARGENTINO: REGLAS, EXCEPCIONES Y PRINCI- PIOS. ALGUNAS DIFICULTADES ACTUALES}

Al igual que en los Estados Unidos de América nuestra Constitución no prevé expresamente la atribución judicial de controlar la constitucionalidad de las leyes ${ }^{36}$ como sucede en todos los países de Latinoamérica, y en las constituciones provinciales. De la misma manera que en el país del Norte, el nacimiento del control de constitucionalidad se gestó jurisprudencialmente a partir de los casos Sojo (1887) y Elortondo (1888) 37 .

De todos modos, conforme al art. 116 de la CN por el cual el Poder Judicial de la Nación debe conocer y decidir "todas las causas que versen sobre puntos regidos por la Constitución", siendo ésta suprema (art.31) puede interpretarse que el Poder Judicial está obligado a invalidar lar normas contrarias a ella ${ }^{38}$. Por otra parte, el art. $3^{\circ}$ de la ley 27 de 1862 dispuso que uno de los objetos de la justicia nacional "es sostener la observancia de la Constitución nacional, prescindiendo, al decidir las causas, de toda disposición de cualquiera de los otros poderes nacionales, que esté en oposición con ella”.

Las reglas del control del modelo americano han sido adoptadas en general por el sistema federal argentino. Algunas reglas son formales (recogidas por la Constitución o la ley) y otras jurisprudenciales. A su vez la CSJN a través de su jurisprudencia ha flexibilizado algunas reglas, a través de excepciones; y ha

34. En Neuquén, la ley especial 2130 regula el procedimiento ante el Tribunal Superior.

35. La acción directa de inconstitucionalidad por ante el Tribunal Superior de Justicia está reglamentada por la ley 402, del año 2000.

36. Sólo con la reforma constitucional de 1994 se lo estableció expresamente, en el marco del amparo, conforme al nuevo art. 43.

37. Desde su constitución (1863), la Corte Suprema ejerció el control de constitucionalidad sobre normas reglamentarias o legales. En Sojo no lo hace expresamente, optando por no aplicar la norma cuestionada. Pero al año siguiente, en el caso Elortondo, que trataba sobre la expropiación de terrenos para construir la Avenida de Mayo y donde se cuestionaba si la facultad del Poder Legislativo para declarar la utilidad pública podía cubrir un espacio mayor que el necesario para la obra pública, la Corte admitió el derecho de la actora a que se limitara el poder expropiatorio, declarando la inconstitucionalidad de la norma nacional, en cuanto excedía lo requerido estrictamente para la construcción de la avenida (Fallos, 33:193).

38. Néstor Pedro Sagüés, "El control de constitucionalidad en la Argentina”, en Sabsay (dir) Constitución de la Nación Argentina, t. 4, 585 a 602. 
otorgado en los últimos años gran relevancia a los principios, particularmente por influencia del llamado control de convencionalidad edificado primordialmente sobre principios en ausencia de reglas ${ }^{39}$.

Es que uno de los temas que mayor interés ha despertado en la teoría del derecho a partir de la segunda guerra mundial es la mayor importancia de los principios generales. La crisis de legitimidad del órgano legislativo, la consecuencial pérdida de fuerza normativa de la ley, la necesidad de limitar el ejercicio del poder y el paso de la racionalidad en la aplicación de la regla a la razonabilidad o logos de lo humano, son aspectos entre otros, que motivaron el surgimiento de un discurso estructurado alrededor de los principios, dirigido a demostrar que la decisión judicial no se soporta únicamente en normas tipo regla (de aplicación subsuntiva del modo todo o nada).

Fue en la década del sesenta del siglo pasado, con la crítica de Ronald Dworkin al positivismo jurídico representado por Hart, en la que surge un marcado interés por el tema de los principios. A ello se suma, en la década del ochenta, la preocupación de Robert Alexy por proteger los mismos como fundamento de los derechos fundamentales.

Se encuentran así definidas dos líneas de pensamiento: la dworkiana dirigida a rechazar el modelo de reglas y a explicar o justificar el razonamiento judicial en los denominados casos difíciles en base a principios $^{40}$, y la alexyana cuyo principal punto de interés es el desarrollo de una teoría constitucional de los principios como fundamento de los derechos fundamentales ${ }^{41}$.

Tanto Dworkin como Alexy coinciden en formular diferencias estructurales entre reglas y princi$\operatorname{pios}^{42}$. A partir de allí, señalan que mientras las reglas se aplican del todo o nada (carácter disyuntivo), en los principios se debe atender a las circunstancias jurídicas y fácticas.

Desde el derecho romano las reglas se entendieron como una proposición que expone en forma breve el derecho vigente. Eran normas imperativas del ordenamiento. Con el iuspositivismo surge la

39. La Corte IDH ha justificado el nacimiento del control de convencionalidad en principios del derecho internacional tales como la tesis del efecto útil de los tratados como método de interpretación de los órganos internacionales; el principio de buena fe; y el principio de pacta sun servanda. Asimismo, el ejercicio del control de convencionalidad se construye en base a principios, tales como subsidiaridad; pro homine; universalidad; igualdad o no discriminación; efectividad; irrenunciabilidad; indivisibilidad; intransigibilidad, etc. No existe ninguna regla en la Convención Americana de Derechos Humanos que establezca esta competencia a cargo de la $\mathrm{CIDH}$

40. Señala Dworkin: "Me propongo llevar un ataque general contra el positivismo y, cuando sea necesario dirigirlo contra un blanco en particular, usaré como tal la versión de H.L.A Hart. Mi estrategia se organizará en torno del hecho de que cuando los juristas razonan o discuten sobre derechos y obligaciones jurídicas, especialmente en aquellos casos difíciles en que nuestros problemas con tales conceptos parecen agudizarse más, echan mano de estándares que no funcionan como normas, sino que operan de manera diferente, como principios, directrices políticas y otros tipos de pautas". Los derechos en serio, Trad. Marta Guastavino. (Barcelona:Ariel, 1984), 72.

41. En ese sentido señala Alexy: "Habrá que mostrar que no es posible una dogmática adecuada de los derechos fundamentales sin una teoría de principios". Teoría de los derechos fundamentales, Trad. Ernesto Garzón Valdés, Madrid: Centro de Estudios Constitucionales, 1993, p. 25.

42. En Dworkin se pueden leer esas diferencias entre principios y reglas en las páginas 74-80; en Alexy en las páginas 81 a la 104. 
moderna teoría general del derecho para la cual, como dice Bobbio ${ }^{43}$ el derecho es una ciencia autónoma que funciona a base de reglas o normas positivas y el jurista debe limitarse a aplicar la solución prevista en la ley general y abstracta, de modo que el intérprete no ańada nada nuevo a su significado. Desde esa óptica las reglas constituyen la base de la aplicación y de la interpretación del derecho.

En conclusión, las reglas son normas que exigen su pleno cumplimiento, es decir, sólo pueden ser cumplidas o incumplidas. Las reglas son aplicables en la forma de todo o nada y, suelen identificarse con la norma escrita, ya sea ésta ley o reglamento.

Los principios están ubicados en el plano deóntico. Mientras las reglas son normas cuyo texto establece una prescripción que sólo puede ser cumplida o incumplida, los principios son normas que ordenan la realización de algo de la mejor manera posible.

Para Robert Alexy los principios son mandatos de optimización. Las posibilidades jurídicas de la realización de un principio están determinadas esencialmente, a más de por las reglas, por los principios opuestos. Esto significa que los principios requieren ponderación. La ponderación es la forma característica de la aplicación de los principios” ${ }^{4}$.

En otras palabras los principios solamente juegan en la interpretación cuando la aplicación directa y exclusiva de las reglas no da la solución al problema jurídico, es decir cuando el intérprete está frente a casos difíciles.

Sin embargo algunos juristas sostienen que los principios han de tenerse siempre en cuenta en la aplicación del derecho y sólo después de hacerlo podemos afirmar que un caso es fácil o difícil; un caso es fácil -escriben- precisamente cuando la subsunción de unos hechos bajo una determinada regla no resulta controvertible a la luz del sistema de principios, motivo por el cual, antes de decidir que una norma es concluyente para resolver un caso, siempre es preciso deliberar a partir de las razones que nos proporcionaron los principios, tanto en relación con los hechos como respecto de la norma o regla" ${ }^{35}$.

El sistema de control federal argentino se encuadra principalmente en reglas. Algunas, como veremos, fueron flexibilizadas jurisprudencialmente a través de excepciones.

1. Es judicial y difuso, pues se ejerce por todos los jueces de cualquier jurisdicción y competencia y solo el poder judicial tiene a su cargo el control ${ }^{46}$.

43. Bobbio, Norberto. Teoría general del Derecho, (Bogotá: Temis 1997), 3.

44. Alexy, Robert, El concepto y la validez del derecho, (Barcelona: Editorial Gedisa), 1994, 75.

45. Prieto Sanchiz, Luis. Sobre Principios y Normas. Problemas del razonamiento jurídico, (Madrid: Centro de Estudios Constitucionales, 1992), 155.

46. Así lo decidió la Corte Suprema en Ingenio y Refinería San Martín del Tabacal S.A. c/Provincia de Salta en 1967. Dijo allí que cualesquiera sean las facultades del poder ejecutivo para dejar sin efecto actos contrarios a las leyes, no cabe 
2. El máximo tribunal del país es la CSJN, la que tiene por regla competencia originaria y exclusiva (art. $117 \mathrm{CN}$ ), por apelación ordinaria (art. 116) ${ }^{47}$ y por apelación extraordinaria ${ }^{48}$

3. Si bien no rige normativamente el precedente obligatorio, la CSJN ha decidido dar a su jurisprudencia efecto vinculante, configurando una regla de derecho constitucional consuetudinario. A estos efectos argumentó primero que los jueces tienen el deber moral de seguir sus decisiones ${ }^{49}$, y luego un deber institucional ${ }^{50}$, pudiendo apartarse del criterio de la Corte Suprema, pero dando fundamentos de las razones. En algunos casos, la Corte Suprema ha hablado del deber de los tribunales inferiores de someterse a sus precedentes, dada la autoridad institucional de sus fallos en su carácter de último intérprete de la Constitución nacional ${ }^{51}$.

4. Rige la regla de causa o caso (art. $116 \mathrm{CN}$ y art. $2^{\circ}$ de la ley 27 que prescribe que los tribunales federales sólo ejercen jurisdicción en casos contenciosos). Es decir que los jueces sólo pueden expedirse dentro de los litigios que tramiten ante ellos entre dos partes antagónicas con pretensiones encontradas. En consecuencia, se detrae al juez todo lo que sea consulta, dictamen, declaración teórica, o general, o abstracta. La CSJN fue inicialmente muy estricta con el concepto de caso $^{52}$, el que se fue flexibilizando sin eliminarse a partir del nacimiento pretoriano de la acción declarativa de inconstitucionalidad ${ }^{53}$ construida sobre la acción declarativa de certeza prevista en el art. $322 \mathrm{CPCC}^{54}$.

admitir que sea de su competencia el declarar la inconstitucionalidad de éstas, porque el poder judicial es, en última instancia, el único habilitado para juzgar la validez de las normas dictadas por el órgano legislativo. Esto resulta imperativo -según la Corte- tanto para el estado federal como para las provincias.

47. La competencia ordinaria de la Corte Suprema deriva de este artículo que establece la competencia federal, y lo es siempre por apelación. Corresponde intervenir cuando de esa materia se trate

48. La competencia extraordinaria de la Corte Suprema en ejercicio del control de constitucionalidad deriva del artículo 116 de la CN en tanto dispone que corresponde a la Corte Suprema y a los tribunales inferiores el conocimiento y decisión de todas las causas que versen sobre puntos regidos por la Constitución; del art. 31, que establece el principio de supremacía y el orden jerárquico del derecho positivo, y del art. 75, inc. 22, que otorga superioridad a los tratados respecto de las leyes y reconoce jerarquía constitucional a los tratados de derechos humanos allí enunciados y a los que en el futuro la obtengan. Asimismo, el art. 43, como consecuencia de la reforma constitucional de 1994, dispuso que en el caso de la acción de amparo el juez podrá declarar la inconstitucionalidad de la norma en que se funde el acto u omisión lesiva.

49. Fallos, 25:368.

50. Fallos, 212:59.

51. Fallos, 315:2386.

52. Fallos : 12-372; 24-248; 95-290; 107-179; 115-163; 156-318; 242-353; 256-104; 317-341; entre muchos otros.

53. Fallos : 307-1379 "Provincia de Santiago del Estero c/Estado Nacional y/o Yacimientos Petrolíferos Fiscales - Acción de Amparo", fallada el 20 de agosto de 1985

54. Fallos :10-606;310-977;310-1794;310-2812;311-421;312-1003;314-1186;315-1013;308-2569;314-1186;3162206;316-2855; 317-1224;320-1875;322-678;322-1135;322-2799;323-19;323-1849;323-107; 323-3277;323-4193;324-

871;324-2315, entre muchos otros. 
5. Rige la regla de la legitimidad (standing). El sujeto que tiene legitimación activa para provocar el control indirecto es el titular del derecho que se intenta valer. No hay acción sin interés, ni recurso sin agravio $^{55}$. La ley o el acto presuntamente inconstitucionales deben causar gravamen al titular actual de un derecho, es decir, aquél que ostenta un interés personal y directo comprometido por el daño al derecho ${ }^{56}$.

6. Es incidental o indirecto, dado que no hay, por regla, una vía directa por medio de la cual sea factible propo $\neg$ ner una acción de inconstitucionalidad pura o directa ante la Corte Suprema de Justicia, como vimos existe en los sistema latinoamericanos y en el derecho provincial. Sin perjuicio de ello, podemos considerar al amparo a partir de la reforma de 1994 y a la acción de inconstitucionalidad creada pretorianamente por la CSJN sobre la acción declarativa de certeza (art. 322 CPCC) como vías impuras directas de control, que pueden llegar a la CSJN por apelación o plantearse ante la misma en los casos de competencia originaria previstas en el art. $117 \mathrm{CN}$.

7. El control es amplio en lo que se refiere a la materia susceptible de control, pues recae sobre cualquier norma o acto de jerarquía inferior a la Constitución . ${ }^{57}$

8. La Corte Suprema argentina ha elaborado la doctrina de las cuestiones políticas no judiciables, que se basa en el principio de división de poderes reconociendo facultades privativas de los poderes del Estado $^{58}$.

9. Los efectos de las sentencias son inter partes -es decir se circunscriben al caso concreto- careciendo de efecto erga omnes ${ }^{59}$. Es decir que lo decidido en una causa se aplica sólo a ella, sin derogar

55. Hitters, "La jurisdicción constitucional en Argentina”, en García Belaunde-Fernández Segado (coords) La jurisdicción constitucional en Iberoamérica, p. 283 a 305.

56. Conforme a la jurisprudencia de la Corte Suprema, el agravio constitucional no puede invocarse cuando: a) El agravio deriva de la propia conducta discrecional del interesado; b) Ha mediado renuncia a su alegación; c) Quien formula la impugnación se ha sometido anteriormente sin reserva alguna al régimen jurídico que ataca; d) Quien formula la impugnación no es titular del derecho presuntamente lesionado; e) No subsiste el interés personal en la causa, sea por haber cesado la presunta violación al derecho, sea por haberse derogado la norma cuya inconstitucionalidad se alegaba, etc., con lo que la cuestión judicial a resolver se ha tornado "abstracta".

57. Son controlables mediante el control de constitucionalidad las leyes, decretos, ordenanzas, reglamentos, actos administrativos, sentencias, trata $\neg$ dos internacionales, constituciones provinciales, actividad de los particulares, e incluso la propia reforma de la Constitución federal, que emana del poder constituyente derivado.

58. Con independencia del estado actual de esta doctrina y de la mayor o menor extensión que las distintas composiciones de la Corte Suprema le han conferido, creemos que es uno de los pilares del control de constitucionalidad. Hemos abordado el tema en "Las cuestiones políticas no justiciables", en Máximos Precedentes de la Corte Suprema de Justicia de la Nación (Pablo Manili Director), capítulo VI, tomo I; (Buenos Aires:Editorial La Ley, 2013) y en "Cuestiones políticas y cuestiones no judiciables”, Tratado de Derecho Procesal Constitucional, Tomo I, p. 453-469, (Buenos Aires: Editorial La Ley, junio de 2010).

59. Sin perjuicio de este principio, característico del sistema, en función del modelo, la Corte Suprema de Justicia ha extendido los efectos de algunas de sus sentencias de manera plural; tal el caso en CSJN, 24/2/09, Halabi, Ernesto c/PEN ley 25.873 y decr. 1563/04 s/amparo, LL, 2009-B-157, y JA, 2009-II-608, donde el alto tribunal dio nacimiento pretorianamente a las ac $\neg$ ciones de clase. 
a la norma reputada inconstitucional y sin afectar a las normas análogas ${ }^{60}$ ni a normas futuras ${ }^{61}$. Si se declara inconstitucional una parte de la ley, el resto permanece intacto ${ }^{62}$.

10. Por medio del recurso extraordinario (reglas de los artículos 14, ley 48; 256 a 258, CPCCN) se puede recurrir por ante la Corte Supre $\neg$ ma de Justicia de la Nación, a fin de que ejerza el control de constitucionalidad. Éste es un canal excepcional que se apoya en el art. 116 de la $\mathrm{CN}$, configurando la llamada cuestión federal o cuestión constitucional, que puede ser simple o compleja ${ }^{63}$, y ésta, a su vez, directa o indirecta ${ }^{64}$.

11. La Corte Suprema por regla tiene un alto margen de discrecionalidad en la selección de los asuntos. La ley 23.774, creó el instituto del certiorari modificando el artículo 280 del CPCC que regula la admisibilidad del recurso extraordinario, le permite según su sana discreción, y con la sola in $\neg$ vocación de esa norma rechazar el recurso extraordinario o la queja por denegación de extraordinario por falta de agravio federal suficiente o cuando las cuestiones planteandas resultan insustanciales o carentes de trascendencia.

12. Otra regla restrictiva con que cuenta el tribunal son las precisas limitaciones de interposición del recurso extraordinario y del de queja que impuso la Corte Suprema por la Acordada No 4/07, de fecha 16 de marzo de 2007, con fundamento en reiterados precedentes relacionados con la admisibilidad formal de dichos recursos.

13. La CSJN creó pretorianamente en su oportunidad ${ }^{65}$ la avocación per saltum, como una nueva forma de control constitucional ante la existencia de gravedad institucional, abocándose a su conocimiento sin que el pleito le sea llevado por vía impugnativa. Hoy este instituto se encuentra reglamentado en los artículos 257 bis y 257 ter del CPCC.

Ahora bien, no podemos obviar las dificultades que el sistema federal ha dejado en evidencia a lo largo de los últimos ańos. La primera emerge de la clásica falta de uniformidad de las decisiones en el

60. Fallos, 253:253.

61. Fallos, 247:325.

62. Fallos, 214:177

63. La primera tiene que ver con la mera y pura interpretación de la Constitución, las leyes federales, los tratados internacionales, las reglamentaciones a las leyes federales y los actos federales de las autoridades del gobierno federal. La segunda aparece cuando existe un conflicto entre una norma o acto, sea federal o local, y la Constitución.

64. La cuestión federal compleja directa implica un conflicto entre la Constitución federal y una ley nacional, un tratado, un acto de autoridad federal, una norma provincial, y una norma o acto de autoridad local. La cuestión federal compleja indirecta tiene en miras un conflicto entre las normas y actos federales, o entre normas y actos federales y locales que indirectamente agreden a la Constitución federal, Hitters "La jurisdicción constitucional en Argentina", García Belaunde-Fernández Segado (coords) La jurisdicción constitucional en Iberoamérica, 298.

65. CSJN, 6/9/90, “Dromi, José R. s/avocación en "Fontela, Moisés E. c/Estado nacional”, LL, 1990-E-97; LLC, 1990854, y DJ, 1990-2-788. Otro ejemplo, casos "Fayt" y "Shiffrin". 
modelo difuso si existe ausencia normativa de la obligatoriedad del precedente. Un Juez puede reputar constitucional una ley, y otro resolver lo contrario en casos casi análogos. Es cierto que el modelo difuso es, como dijimos, un sistema de casos concretos, por lo cual la constitucionalidad o no de una norma solo afecta a las partes del pleito. Pero este diseńo ha evidenciado notorios desequilibrios ante normas generales de emergencia (lamentablemente en Argentina más habituales que excepcionales) que afectan a colectivos con igual incidencia y que tienen diferentes resultados según sea el juez que toque en suerte.

Esta situación lesiona el principio de igualdad ante la ley ${ }^{66}$. Además, si no median recursos idóneamente interpuestos contra esos fallos los mismos pueden quedar firmes, circunstancia que posibilita que el sistema judicial dé respuestas contradictorias. Es cierto el recurso extraordinario federal previsto en el artículo 14 de la Ley 48 permite llevar todo expediente donde se decida la constitucionalidad o inconstitucionalidad de una norma presuntamente opuesta a la Constitución federal ante la Corte Suprema, pero como es sabido este recurso puede ser desestimado por la Corte en razón del amplio margen de discrecionalidad que la misma tiene para aceptar los recursos, particularmente a partir del advenimiento del llamado certiorari negativo ${ }^{67}$.

Otra hipótesis contradictoria se da cuando una norma puede ser reputada en un fallo como constitucional, pero en otro posterior del mismo tribunal inconstitucional ${ }^{68}$. Estos cambios denominados overrulings son frecuentes cuando la integración de la Corte ha variado, alternativa que en Argentina ocurre con frecuencia. Algunas veces la Corte recurre al argumento de las inconstitucionalidades sobrevinientes, es decir una norma pudo haber sido constitucional al momento de sancionarse pero después por modificación del contexto fáctico o normativo concluye como inconstitucional ${ }^{69}$.

Es cierto que la CSJN ha decidido dar a su jurisprudencia efecto vinculante, configurando una regla de derecho constitucional consuetudinario, llegando recientemente ${ }^{70}$ a Declarar que la doctrina judicial de esta Corte referida a la interpretación del art. 67 inc e) del Código Penal es de seguimiento

66. Sobre la relación del principio de igualdad y la jurisprudencia obligatoria ver Bidart Campos Germán J., La jurisprudencia obligatoria, La Ley 2001-F 1492 - LLP. Por ejemplo, los depósitos bancarios en dólares que fueron pesificados fueron recuperados por algunas personas en dólares billete, por otras en pesos al valor del dólar libre, por otras al valor de la pesificación (1/1), por otras a una equivalencia intermedia que se llamó "esfuerzo compartido". Incluso hubo personas que nada recuperaron. Ver al respecto nuestra crítica en ¿Está en crisis nuestro control federal de constitucionalidad?, (Buenos Aires: Editorial La Ley, Suplemento especial $70^{\circ}$ Aniversario, noviembre de 2005) y La doctrina plenaria frente a la doctrina de la Corte Suprema, (Buenos Aires: Editorial La Ley, Doctrina Judicial, año XXIV, No 22, mayo de 2008). 67. Artículo 280 CPCyC.

68. Como sucedió por ejemplo con las leyes de obediencia debida y punto final, donde una composición de la Corte Suprema las consideró constitucionales y otra posterior inconstitucionales.

69. Ejemplo casos Sejean. CSJN Fallos 308:2268 e Izcovich CSJN Fallos 328:2566.

70. Autos Recurso de hecho deducido por la defensa en la causa Farina Haydée S. s/ homicidio culposo, sentencia del 26/12/2019. Ver comentarios de Néstor Sagüés, Sergio Barotto y Andrés Gil Domínguez en diario La Ley, viernes 29 de mayo de 2020 
obligatorio para todos los tribunales judiciales del país. Pero cabe advertir que la Corte también ha sostenido que "la facultad de interpretación de los jueces y tribunales inferiores, no tiene más limitación que la que resulta de su propia condición de magistrados, y en tal concepto pueden y deben poner en ejercicio toda sus aptitudes y medios de investigación legal, científica o de otro orden, para interpretar la ley, si la jurisprudencia violenta sus propias convicciones"71, tesis que obligaría a olvidar la eficacia vinculante de sus fallos. Algo similar ocurre, cuando la Corte restringe su jurisprudencia obligatoria al señalar que sus precedentes carecen de fuerza legalmente vinculante para los tribunales locales en materia de derecho público local ${ }^{72}$.

En definitiva, si bien existe hoy una regla de derecho consuetudinario constitucional elaborada por la propia Corte Suprema que impone a los tribunales inferiores el deber jurídico de seguir sus criterios en todo los escenarios (derecho federal, común o local) la misma se encuentra condicionada ya que el tribunal inferior siempre puede sentirse habilitado para apartarse de ella en la medida que lo haga de modo expreso y dé fundamentos valederos y diferentes a los ya examinados por la Corte, sin perjuicio de señalar que los tribunales inferiores han tenido siempre actitudes disímiles frente a la doctrina de la Corte $^{73}$.

Si bien es loable y deseable el esfuerzo que la CSJN hace en el caso Fariña ${ }^{74}$ para sostener la obligatoriedad vertical y externa de sus precedentes, un dejo de frustración nos deja la cita de las sentencias dictadas en el recordado caso Sosa ${ }^{75}$, que fueron incumplidas por la Provincia de Santa Cruz, dejando a luz en cruda evidencia la necesaria normatividad del precedente obligatorio.

La invocación siempre presente del conocido caso de la Corte Suprema de los Estados Unidos Cooper v. Aron (1958) como referencia de la creación pretoriana del stare decisis, tiene según nuestra forma de ver valor relativo en razón de las distintas raíces culturales de las tradiciones jurídicas en danza: de derecho común (en los Estados Unidos); y de derecho continental (en el país), las que otorgan diferente rol al juez como creador del derecho.

71. Fallos 131:109, 263:255

72. Fallos, 304:1459

73. Efectivamente, algunas veces hay actitud de obediencia; en otras ocasiones se pregona una suerte de sometimiento parcial: habrá de seguirse a la Corte Suprema en temas de derecho federal, pronunciados en virtud del recurso extraordinario federal, pero no en asuntos de derecho "común" (civil, comercial, penal, laboral), sobre los cuales muchas veces la Corte Suprema se expide en instancia originaria y exclusiva. Estos asuntos, en principio, son de competencia de las jurisdicciones ordinarias provinciales, a tenor del artículo 75 inciso 12 de la Constitución Nacional. De cuando en cuando se habla del sometimiento moral a las sentencias de la Corte Suprema, pero no legal (en los hechos, ello parece entenderse como un seguimiento más tenue y en definitiva no coercitivo). Ciertas sentencias exigen, para obedecer a la jurisprudencia de la Corte Suprema, que ella sea reiterada. En una postura igualmente exigente, algunos tribunales demandan que el fallo de la Corte Suprema con efectos expansivos, sea dictado por unanimidad. Si no tiene tal cualidad, disminuye su peso jurídico. A su turno, una colección de fallos se inclina por el no acatamiento a las doctrinas sentadas por la Corte Suprema federal, salvo desde luego que el órgano tribunalicio del caso, voluntariamente, las comparta.

74. CSJ 2148/2015/RH1.

75. Entre otros fallos 325:2723. 
La recurrente inestabilidad del derecho argentino motiva proponer como modificación legal ${ }^{76}$ la obligatoriedad vertical y externa de los fallos de la CSJN en temas de derecho federal y común, dejando excluidos los temas de derecho local. Si apartarse de la doctrina del último intérprete constitucional del sistema constituye siempre caso constitucional ${ }^{77}$, por sobre la característica que la norma interpretada sea de derecho federal o común, cuando el Alto Tribunal interpreta derecho lo hace en una "función constitucional" o en ocasión de un "caso constitucional", por lo cual sus fallos y su doctrina debería ser siempre obligatoria para los tribunales inferiores; y para todos los órganos públicos por ser el último intérprete de la Constitución y así debería regularse normativamente.

\section{LAS CONSULTAS PREVIAS DE CONSTITUCIONALIDAD: UN RECORRI- DO POR EL DERECHO COMPARADO.}

A los fines de este trabajo es importante formular una mirada a nuestro alrededor con la ayuda del derecho comparado, que siempre constituye una herramienta valiosa para evaluar nuestras instituciones y sus eventuales cambios.

Hace tiempo que el debate sobre el control previo (la consulta intentada por el Senado es una especie del control previo) está colmado y compactado. Históricamente porque formó parte del proceso dogmático de construcción del sistema europeo de justicia constitucional, y pragmáticamente porque el control previo de constitucionalidad está más extendido de lo que se piensa.

En Europa la mayoría de países cuenta en sus sistemas de control con alguna variante de control previo. En América Latina, dado el crisol de sistemas de control constitucional, muchos de ellos también poseen alguna forma de control de constitucionalidad a priori.

Las modalidades son muy diversas, aunque cabe agruparlas en tres grandes técnicas: controles previos conflictuales; controles previos abstractos; y controles veto ${ }^{78}$.

Los primeros son aquellos mecanismos en los que normalmente los Gobiernos de una federación instan ante la jurisdicción constitucional un control preventivo sobre normas de los Estados federados, ya sea que estas normas estén en trámite parlamentario o hayan sido aprobadas, pero antes de su entrada en vigencia. El objeto habitualmente es comprobar si invaden competencias de la Federación ${ }^{79}$. Los

76. Recordemos que el legislador alguna vez dispuso que los jueces inferiores debían seguir la jurisprudencia de la Corte Suprema en asuntos análogos (así lo hizo el artículo 19 de la Ley 24.463, en materia previsional, aunque tal precepto se encuentra hoy derogado por la Ley 26.025).

77. CSJN, Fallos: 304:494; 307:483 y 2124; 308:215; 310:1769; 312:2187, entre otros.

78. Estas técnicas no son incompatibles entre sí y en algunos casos, como el portugués, se utilizan todas conjuntamente. Ver Ignacio Villaverde Menéndez, El control previo de constitucionalidad de las normas con rango de ley. Crónica de un escéptico, Revista Catalana de dret públic, No 49, www.rcdp.cat y Ángel José Gómez Montoro, "El control previo de constitucionalidad de proyectos de estatutos de Autonomía y demás leyes orgánicas", Revista Española de Derecho Constitucional, Año 8, № 22, (enero-abril 1988).

79. Artículo 138.2 de la Constitución Austriaca. 
segundos son los controles tipo del modelo francés, que suelen limitar el control previo a determinado tipo de normas que gozan de una especial relevancia constitucional, como los tratados internacionales; las leyes reguladoras de derechos fundamentales; los reglamentos parlamentarios; las leyes institucionales o de reforma constitucional, etc).

Los terceros son controles que en realidad son la expresión de una función consultiva, habitualmente en el marco de un procedimiento de veto de la Jefatura del Estado a normas con rango de ley ${ }^{80}$. Existen también aquellos sistemas que incorporan mecanismos alternativos, bien de consulta o de resolución previa de conflictos inter-orgánicos sobre la competencia constitucional para dictar una norma, su constitucionalidad o la del procedimiento elegido para su aprobación, como sucede con los sistemas de Suecia y Canadá ${ }^{81}$.

Presentado el tema, centraremos nuestra atención en algunos de los modelos mixtos de Latinoamérica que entendemos de mayor interés, por la fuerte presencia del control previo, en este recorrido por el derecho comparado: Chile; Guatemala; y Costa Rica.

El Tribunal Constitucional Chileno ${ }^{82}$, es quizás uno de los modelos concentrados más puros de Latinoamérica y cercanos al modelo francés ${ }^{83}$. El Tribunal realiza control preventivo y posterior de preceptos legales (incluidos los decretos con fuerza de ley); en este último caso, ya sea por la vía de requerimientos de inaplicabilidad o de acciones de inconstitucionalidad.

Los controles preventivos se clasifican en facultativos (a requerimiento del Presidente de la República, de las Cámaras o de una parte de sus miembros en ejercicio) y obligatorios (respecto de leyes interpretativas de la Constitución, leyes orgánicas constitucionales y tratados internacionales que contengan normas propias de este último tipo de leyes). El Tribunal también controla, en forma preventiva y facultativa los proyectos de reforma constitucional y los tratados internacionales sometidos a la aprobación del Congreso.

La consulta optativa se realiza durante la tramitación del proyecto en cuestión y antes de su promulgación. Según la Constitución la legitimación recae en el Presidente de la República; las Cámaras;

80. El artículo 26 de la Constitución de la República de Irlanda contiene un procedimiento de veto presidencial a las leyes aprobadas por el Parlamento irlandés. El presidente de la República puede someterlas a examen por la Corte Suprema antes de su firma y promulgación. Si esta las considera contrarias a la Constitución, el presidente no puede firmar y promulgar la ley.

81. Los artículos 20 y ss. de la Constitución sueca crean el Consejo sobre Legislación, con una función consultiva integrado por jueces o antiguos jueces del Tribunal Supremo. En Canadá, la Corte Suprema puede emitir una advisory opinion a instancias del Gobierno federal. Ver Wardell Hogg, Peter, Constitutional Law of Canada, 5. ed, (Toronto, Carswell, 2007), 212 y ss.

82. Ver Christian G. Suarez Crothers, Chile, en Tratado de Control de Constitucionalidad y Convencionalidad (Jorge Alejandro Amaya, Director), Tomo 2, "Sistemas Latinoamericanos", capítulo IV, Buenos Aires, Astrea (2018), 131-183. El TC Chileno está conformado por diez (10) miembros. Su designación es efectuada de la siguiente manera: tres (3) nombrados por el Presidente de la República, cuatro (4) designados por el Congreso Nacional: y tres (3) elegidos por la Corte Suprema de Justicia. Estos funcionarios son nombrados para desempeñar sus cargos por el período de 9 años, con el carácter de inamovibles y sin posibilidad de reelección.

83. Constitución Política de la República de Chile, Tribunal Constitucional de Chile http://www.tribunalconstitucional. $\mathrm{cl} / \mathrm{wp} /$ normas. 
o en una cuarta parte de sus miembros y está regulada en la Ley Orgánica del Tribunal. El Tribunal determinará si el proyecto consultado se encuentra viciado total o parcialmente de inconstitucionalidad. De encontrarse vicios, las disposiciones que se declaren contrarias a la Constitución no podrán transformarse en ley ${ }^{84}$.

Si el proyecto consultado se estima constitucional, no podrá ser declarado posteriormente inaplicable por el mismo vicio materia del proceso y de la sentencia respectiva ${ }^{85}$. Contra dicha sentencia y las resoluciones no cabe recurso, sin perjuicio de ello, el Tribunal Constitucional tiene la potestad de subsanar sus errores ${ }^{86}$.

La Corte Guatemalteca de Constitucionalidad ${ }^{87}$ tiene competencia originaria y de apelación. En el primer caso, en el conocimiento de las impugnaciones contra leyes o disposiciones generales objetadas de inconstitucionalidad total o parcialmente; y resuelve las cuestiones de competencia entre organismos y entidades autónomas del Estado. En el segundo, resuelve las apelaciones interpuestas en los procesos de amparo tramitados en cualquier tribunal, y las impugnaciones de inconstitucionalidad contra leyes en casos concretos en cualquier proceso judicial ${ }^{88}$.

Cuenta con funciones vinculadas con el control preventivo. En dicho caso, se pronuncia respecto de la constitucionalidad de tratados, convenios internacionales y proyectos de ley, a petición de cualquier órgano del Estado; la opinión sobre las leyes vetadas por el Poder Ejecutivo por razones de inconstitucionalidad; y emite dictamen previo sobre los proyectos de reformas constitucionales; y reforma a la Ley de Amparo, Exhibición Personal y de Constitucionalidad ${ }^{89}$.

84. Constitución Política de la República de Chile, artículo 94.

85. Ley Orgánica Constitucional del Tribunal Constitucional de Chile, artículo 71.

86. Constitución Política de la República de Chile, artículo 94.

87. Sobre la Corte Constitucional de Guatemala ver Mauro R. Chacón Corado, "Guatemala, en Tratado de Control de Constitucionalidad y Convencionalidad” (Jorge Alejandro Amaya, Director), Tomo 2, Sistemas Latinoamericanos, capítulo VII, Buenos Aires, Astrea (2018), 251-282. La Corte está integrada por cinco (5) magistrados titulares que duran cinco (5) años en sus funciones con posibilidad de reelección, cada uno de ellos con su respectivo suplente; empero, cuando conoce de asuntos de inconstitucionalidad en contra de la Corte Suprema de Justicia, el Congreso de la República, el Presidente o el Vicepresidente de la República, el número de sus integrantes se eleva a siete, escogiéndose los otros dos magistrados por sorteo de entre los suplentes (art. 269 Constitución de Guatemala). Intervienen en los nombramientos la Corte Suprema de Justicia, el Congreso de la República, el Presidente de la República en Consejo de Ministros, el Consejo Superior Universitario de la Universidad de San Carlos de Guatemala, y el Colegio de Abogados. A cada una de estas autoridades le corresponde nombrar a un magistrado

88. Ver Eguiguren Praeli, Francisco, Los Tribunales Constitucionales en Latinoamérica: una visión comparada, (Buenos Aires: Argentina. Honrad Adenauer-Stiftunh AC. 2000), 39.

89. Conforme los artículos 272 de la Constitución Política guatemalteca y 163, inciso e) y 164, inciso b, de la Ley de Amparo, Exhibición Personal y de Constitucionalidad, le corresponde emitir opinión sobre la constitucionalidad de los tratados, convenios y proyectos de ley a solicitud de cualquiera de los organismos del Estado, y de los proyectos de ley a solicitud de Congreso. También, como parte del control de constitucionalidad previo debe dictaminar sobre los proyectos de reforma a la Ley de Amparo, Exhibición Personal y de Constitucionalidad, al igual que respecto de la reforma de leyes de rango constitucional. 
Así, producto del control a priori, la Corte emite dictámenes y opiniones consultivas. Ambas poseen diferencias claras. En el caso de los dictámenes, la legitimación para solicitarlos corresponde al Congreso de la República. En el caso de las opiniones consultivas, la legitimación recae en el Congreso; el Presidente de la República; y en la Corte Suprema de Justicia ${ }^{90}$.

Ambos procesos constituyen una fiscalización abstracta de proyectos de ley o tratados; sin embargo, cuando el Presidente de la República haya vetado una ley por razones de inconstitucionalidad, este proceso debe plantearse, obligatoriamente, por parte del Congreso de la República. Asimismo, en el caso de las opiniones consultivas, lo que estipule la Corte no es vinculante para los consultantes. Mientras que, en el caso de los dictámenes, el criterio estipulado sí vincula al Congreso.

A su vez, el control de constitucionalidad que ejerce la Corte mediante la opinión consultiva puede ser facultativo u obligatorio. El primer caso se relaciona con los tratados, leyes y convenios internacionales. En el segundo supuesto, la consulta será obligatoria cuando se trata de reformas a leyes constitucionales.

En sistema de control de constitucionalidad de Costa Rica prevé también un control de constitucionalidad preventivo mediante los procesos consultivos que se formulen ante la Sala Constitucional de la Corte Suprema de Justicia ${ }^{91}$. El artículo 96 incisos a) y b) de la ley de jurisdicción constitucional establece taxativamente los mecanismos de control de constitucionalidad ex ante vigentes en el sistema de dicho país.

Se reconoce la consulta preceptiva legislativa que se interpone obligatoriamente cuando se trata de proyectos de reforma constitucional; propuestas de reforma a la Ley de la Jurisdicción Constitucional; y proyectos de aprobación de tratados o convenios internacionales. El inciso b) del citado artículo establece la consulta facultativa legislativa. Su formulación es voluntaria cuando versa sobre cualquier otro proyecto de ley que no sea de los supuestos contemplados para la consulta preceptiva. También, procederá para la aprobación legislativa de actos o contratos administrativos, o de reformas al Reglamento de Orden, Dirección y Disciplina Interior de la Asamblea Legislativa. La consulta facultativa sobre proyectos de ley ordinaria es un instrumento que voluntariamente el órgano legislativo puede gestionar ante la Sala con el fin que valore el procedimiento seguido y, eventualmente, el fondo del proyecto consultado 92 .

90. Morales Bustamante, Alejandro, Derecho procesal constitucional, (Guatemala: Ediciones De Pereira, 2a ed, 2012 ), 233. 91. Artículo 10 inciso b) de la Constitución Política y 96 de la ley de la Jurisdicción Constitucional. Sobre el sistema de control de constitucionalidad de Costa Rica ver Adriana Valverde Vargas, Costa Rica, en Tratado de Control de Constitucionalidad y Convencionalidad (Jorge Alejandro Amaya, Director), Tomo 2, "Sistemas Latinoamericanos", capítulo VI, (Buenos Aires: Astrea, 2018), 215-249.

92. Ramírez Altamirano, Marina, Reforma a la Ley de la Jurisdicción Constitucional, Corte Suprema de Justicia, (San José, Costa Rica: 2007), 234. 


\section{EL CASO "FERNÁNDEZ DE KIRCHNER CRISTINA EN CARÁCTER DE PRESIDENTA DEL H. SENADO DE LA NACIÓN S/ACCIÓN DECLARATIVA DE CERTEZA Y LA SENTENCIA DE LA CSJN. ¿HABILITÓ LA CSJN LA CONSULTA LEGISLATIVA?: COMO DECIR SÍ, DICIENDO NO}

En términos concretos la acción declarativa de certeza planteada por el Senado de la Nación directamente ante la CSJN consultándola sobre la validez constitucional de sesionar en forma virtual se resumía en un interrogante:

“Es constitucionalmente posible que tal como lo establece el art. 30 del reglamento de la H. cámara de Senadores sesione mediante medios digitales debido a la situación de gravedad institucional generada objetivamente por el COVID 19?93

Tanto la acción declarativa de certeza (vía procesal elegida) como su variante de control constitucional $^{94}$, requieren entre los requisitos para su procedencia de acuerdo a la regla del art. 322 y a la abundante y reiterada jurisprudencia de la $\operatorname{CSJN}^{95}$ : a) la existencia de un estado de incertidumbre sobre el alcance y modalidad de una relación jurídica concreta; b) la existencia del caso, causa o controversia judicial en los términos de los arts. 116 y 117 y $2^{\circ}$ de la ley 27 ; y c) que la solicitud de certeza no tenga carácter simplemente consultiva, ni importe una indagación meramente especulativa. Asimismo, solo puede habilitarse la competencia originaria y exclusiva de la CSJN en nuestro sistema constitucional conforme las taxativa regla del artículo 117 "En todos los asuntos concernientes a embajadores, ministros y cónsules extranjeros, y en los que alguna provincia fuese parte,..." no pudiendo esta competencia ser extendida por persona o poder alguno ${ }^{96}$.

La sentencia (o respuesta) de la CSJN al interrogante planteado se construye con un voto de mayoría suscripto por los Dres. Maqueda, Highton y Lorenzetti, al que concurre el Dr. Rosatti por sus fundamentos; disintiendo parcialmente el Presidente del Tribunal, Dr. Rosenkrantz.

Por unanimidad el Tribunal decide rechazar formalmente la acción. Sin perjuicio de ello los Dres. Maqueda, Highton, Lorenzetti y Rosatti formulan, obiter dicta, apreciaciones asertivas al interrogante planteado. En pocas palabras, rechazando la acción contestan el interrogante. O diciendo no, responden sí.

Llamaré a los argumentos de los Dres. Maqueda, Higthon y Lorenzetti el voto de las excepciones; a los argumentos del Dr. Rosatti el voto del principio; y a los del Dr. Rosenkrantz el voto de las reglas.

93. Considerando I del voto del Dr. Rosatti

94. Fallos: 307-1379.

95. Fallos: 310-606;310-977;310-1794; 310-2812;311-421;312-1003;314-1186;315-1013;308-2569;314-1186;3162206;316-2855; 317-1224;320-1875;322-678;322-1135;322-2799;323-19;323-1849;323-107; 323-3277;323-4193;324871;324-2315, entre muchos otros.

96. Fallos: 32:120, y reiterado en Fallos: 270:78; 285:209; 302:63; 322:1514; 323:1854; 326:3642, entre muchos otros. 
Como se destacó acertadamente en algunos comentarios al fallo ${ }^{97}$ quizás hubiera bastado acudir a la inexistencia de competencia originaria y exclusiva de la Corte para rechazar el planteo. Al respecto, destacamos dos curiosidades. Primero que solo el voto de las reglas (como no podía ser de otra manera) hace alusión a la ausencia de competencia originaria de la CSJN por no encuadrar el caso en la regla constitucional. Segundo, que era una regla superable a través de un actor distinto que intentara provocar un caso de competencia originaria ${ }^{98}$. Además de la incompetencia cierta del Tribunal, la acción declarativa de certeza jamás podía prosperar formalmente.

No aparecía el estado de incertidumbre requerido, es decir un estado de hecho contrario al derecho, o un estado de incertidumbre sobre el derecho ${ }^{99}$; y mucho menos la imprescindible existencia de un caso o controversia para activar la jurisdicción. En este sentido, con mayor o menor intensidad, todos los Ministros coinciden en sus votos ${ }^{100}$.

Sin dar mayores rodeos, es claro que el interrogante planteado implicó la formulación de una consulta constitucional a la CSJN, quien a través de su reiterada jurisprudencia viene sosteniendo que la acción declarativa y su variante de control constitucional, no tienen por fin un carácter consultivo o una indagación meramente especulativa ${ }^{101}$.

Ahora bien ¿podía la situación de gravedad institucional -objetivamente existente- habilitar al Tribunal para evacuar la consulta? ¿Tiene límites el amplio marco discrecional con que la Corte ha utilizado esta doctrina? ¿O basta frotar su existencia para que el genio aparezca?

97. Ejemplo en los comentarios ya citados de Pérez Sanmartino Osvaldo; Diégues Jorge; y también el de Bianchi Alberto, "La Corte Suprema no es el Consejo de Estado, Instituto de Derecho Constitucional, de la Academia Nacional de Derecho y Ciencias Sociales de Buenos Aires", documento de trabajo, reunión del 16/06/2020.

98. Diegues propone una Provincia afín demandando al Senado; Bianchi provocar un caso de competencia apelada y recurrir al per saltum. La situación de motivar un "caso" nos recuerda el planteo que formulamos patrocinando al Senador Nacional por la Provincia de Corrientes José A. Romero Feris en la impugnación del DNU 1447/92 de intervención al Poder Judicial de la Provincia estando en sesiones ordinarias el Congreso de la Nación. El desafío del planteo pasaba por la legitimación del legislador. Sostuvimos en dicha oportunidad que el senador estaba legitimado para cuestionar el decreto por habérsele privado de sus derechos políticos subjetivos de debatir la intervención en el marco natural del Senado. La acción tuvo favorable acogida en primera Instancia y en la Cámara de Apelaciones. Conf. Amaya Jorge Alejandro, "Un aspecto del Caso Corrientes. La Corte Suprema en deuda con el Federalismo", Boletín de la Asociación Argentina de Derecho Constitucional Nro. 95, Buenos Aires: marzo de (1994).

99. La interpretación del artículo 30 del Reglamento del Senado corresponde exclusivamente al Cuerpo por imperio del principio de división de poderes. Encuadra en la doctrina de las cuestiones políticas no judiciables, estando vedado al Poder Judicial su control, salvo contadas excepciones. Conf. Amaya Jorge Alejandro, "El control jurisdiccional de los interna corporis acta”, Revista de Derecho Público, 2011-1 Control Judicial de la Jurisdicción Administrativa - II, Argentina, Santa Fe: Rubinzal Culzoni, Editores, (6 de mayo de 2011).

100 . Voto de la mayoría considerando $17^{\circ}$; voto concurrente considerandos $3^{\circ}$ y $4^{\circ}$; voto parcialmente disidente considerando $3^{\circ}$

101. Considerando $2^{\circ}$ del voto de la mayoría; $3^{\circ}$ y $4^{\circ}$ voto concurrente; y $3^{\circ}, 4^{\circ}, 5^{\circ}, 6^{\circ}$ y $8^{\circ}$ voto de la disidencia parcial. Con cita de fallos: 320:1556; 330:3777; 340:1338; 341:101, 545; 342:917, entre otros 
La gravedad institucional es a la Corte, lo que la emergencia al Gobierno ${ }^{102}$. Intensifica la interpretación y aplicación de facultades constitucionales, pero no autoriza a olvidarlas o neutralizarlas. Si el genio de la emergencia o de la gravedad institucional todo lo pudiera, la constitución entregaría sus competencias y límites al paladar del poder público de turno.

Así lo recuerda el voto del Dr. Rosatti; y mas lapidariamente el voto del Presidente del Tribunal.

"Que, con todo, no puede desconocerse que la precitada gravedad institucional subyacente en el sub examine no permite obviar el requisito de existencia de "caso" o "causa" a fin de habilitar la intervención de la Corte Suprema en un proceso sometido a su competencia originaria, máxime cuando no se verifica, como es el caso sub examine, ninguno de los supuestos previstos taxativamente en el artículo 117 de la Constitución Nacional. ".... tradicionalmente fue entendida como un mecanismo que tiene por objeto habilitar al Tribunal a superar obstáculos de forma a la procedencia de la jurisdicción apelada de la Corte a la luz del artículo 14 de la ley 48, es decir el recurso extraordinario federal...". "En ese entendimiento, la figura aparece, en su génesis, como inocua a los fines de ampliar la competencia originaria del máximo tribunal argentino, o habilitarla frente a la inexistencia de caso" ${ }^{103}$.

"En suma, la pretensión no puede tener cabida pues la doctrina de la gravedad institucional no puede ser jamás usada para deformar o eludir las exigencias a las que la intervención de esta Corte está constitucionalmente supeditada. La doctrina de la gravedad -institucional, tal como la ha entendido la jurisprudencia del Tribunal, es un instrumento de defensa de la Constitución. Si se la interpretase con la laxitud necesaria para hacer lugar a lo solicitado por la presentante se la habría convertido en una simple coartada para deshonrarla"104.

Creemos que la acción intentada contenía otra falencia. Era auto-contradictoria, al sustentar la consulta en una supuesta imposibilidad de sesionar en la que la propia actora se había situado voluntariamente.

Como dejamos planteado de inicio, el DNU No 297/2020 en su art. 6º exceptuó del aislamiento obligatorio a las actividades consideradas esenciales en la emergencia a los fines del cumplimiento de sus actividades, entre las cuales taxativamente enuncia a las autoridades superiores de los gobiernos nacional, provincial y municipal y a los trabajadores del sector público convocados para garantizar las actividades requeridas por las respectivas autoridades (art. $6^{\circ}$ punto 2.).

No creo necesario aclarar que en una República $\left(\operatorname{art} .1^{\circ} \mathrm{CN}\right)$ el concepto de gobierno está referido a los tres poderes del Estado; y que los tres poderes son esenciales en el marco del funcionamiento de una democracia Constitucional. La adhesión del Senado al aislamiento dispuesto por el DNU que expresa-

102. Utilizamos aquí el concepto de Gobierno en forma restringida. Referida solo a los poderes políticos del Estado.

103. Considerando $9^{\circ}$ del voto del Dr. Rosatti.

104. Considerando $7^{\circ}$ último párrafo del voto del Dr. Rosenkrantz 
mente lo exceptuaba del mismo, constituyó una situación fáctica que lo podría haber inhabilitado para impugnar (o consultar) una situación legal a la que voluntariamente se sometió o en la que voluntariamente se situó, contradiciendo - con la interposición de la acción- la teoría de los actos propios ${ }^{105}$.

¿A qué fundamentos acudió la Corte para dar respuesta a la consulta si no había caso; ni competencia originaria; ni podía expedirse en consulta; ni sortear todas estas reglas invocando la gravedad institucional? No había argumentos jurídicos según la propia Corte, por lo cual acudió a razones políticas para responder la consulta. Razones de excepción (el voto de la mayoría) y razones de principios (el voto concurrente).

De tal manera la CSJN se acercó a las funciones de un Tribunal Constitucional; de un sistema mixto de control; asumiendo una identidad institucional de garante del sistema democrático, propio del modelo concentrado.

El voto de las excepciones anticipa de inicio la respuesta afirmativa al interrogante crucial al utilizar términos como contexto absolutamente extraordinario; y preanunciando que los términos del planteo requiere no solo referir a las reglas de admisibilidad de la acción declarativa de certeza sino “... con igual énfasis seguidamente recordar aquellas que hacen al cumplimiento de las funciones de esta Corte como Tribunal de Justicia y Poder del Estado" y que "Como Tribunal de Justicia y Poder del Estado, las decisiones de la Corte Suprema custodian la Constitución siempre insertas en una realidad histórica (el destacado es propio)"106.

El esfuerzo argumentativo del voto se deposita en la voluntad por responder el interrogante. Basta advertir, que a las reglas de admisibilidad de la acción que conducen al rechazo formal le dedica media carilla ${ }^{107}$; y a los argumentos de la respuesta a la consulta dieciocho páginas.

Navegan estos argumentos por todos los vientos excepcionales (gramaticales, jurídicos y políti$\cos )$.

En los considerandos $3^{\circ}$ y $4^{\circ}$ acude a la famosa frase de Oliver Wendell Holmes en The path of law para justificar la relativización de las reglas jurídicas ("La vida del derecho no ha sido lógica: ha sido experiencia”); recorre su antigua jurisprudencia de estado de excepción citando los casos Alem y Sofía, concluyendo -en forma desafortunada- con la cita del caso Pitto, en el que la Corte de entonces terminó convalidando la destitución por la fuerza de un Presidente democrático acudiendo a un ropaje institucional "Ante la apuntada necesidad de ofrecer respuestas que permitan salidas institucionales en contextos críticos..." 108 .

105. La doctrina de los propios actos ha sido recepcionada desde antiguo por la Corte Suprema de Justicia de la Nación, al advertir que nadie puede ponerse en contradicción con sus propios actos, ejerciendo una conducta incompatible con una anterior conducta deliberada, jurídicamente relevante y plenamente eficaz. Esta regla no sólo es aplicable al derecho privado, sino que alcanza a todas las disciplinas jurídicas. Fallos: 307:1602; 311:1132; 313:367; 323:3035; 336:131, entre muchos otros.

106. Considerando $2^{\circ}$

107. Final del considerando $2^{\circ}$.

108. El Presidente Arturo Frondizi no renunció. Fue llevado preso por las Fuerzas Armadas a la isla Martín García. 
Califica al nacimiento del control de constitucionalidad judicial como "una respuesta excepcional" tanto en los Estados Unidos (Marbury) como en el país (Sojo) ${ }^{109}$; invocando la jurisprudencia del Tribunal que lo condujo, en distintas circunstancias y por diferentes motivos, a crear doctrinas ante situaciones o necesidades de excepción ${ }^{110}$.

Anticipando en el considerando $7^{\circ}$ que no hará primar un criterio formal y afirmando en el $8^{\circ}$ una obviedad (“...no pueden caber dudas entonces de que la continuidad de la tarea de legislar del Congreso de la Nación resulta absolutamente esencial para el normal desarrollo de la vida constitucional de la Argentina”) se pierde luego en disquisiciones históricas y el modo en que han funcionado otro parlamentos en el mundo ante la situación de emergencia, para recorrer luego la historia jurisprudencial de las cuestiones políticas no justiciables y, por supuesto, sus excepciones ${ }^{111}$.

En el considerando $15^{\circ}$ el voto de las excepciones concluye sobre cuáles son las diversas excepciones que el Tribunal guarda respecto de las facultades discrecionales de los otros poderes.

Afirmando que el contenido de la pregunta formulada en la acción entablada por el Senado tiene su respuesta en la interpretación y decisión del propio Senado sobre facultades que la Constitución le confiere al Poder Legislativo ${ }^{112}$, concluye con otra excepción en la parte dispositiva del voto al invertir el obiter dicta y la ratio decidendi, otorgando así centralidad al SI y secundariedad al NO : "Por ello, ... se resuelve que el Senado de la Nación tiene todas las atribuciones constitucionales para interpretar su propio reglamento en cuanto a la manera virtual o remota de sesionar, sin recurrir a la Corte Suprema de Justicia de la Nación; por lo cual se rechaza la acción incoada”.

$\mathrm{Al}$ voto de las excepciones concurre el voto del Dr. Rosatti que lo he denominado el voto del principio, o más precisamente del principio de colaboración inter poderes.

En un extenso voto concurrente, el Dr. Rosatti dedica sus primeros nueve considerandos a explicar minuciosamente las razones por las cuales la acción declarativa de certeza resulta inviable, que coinciden, con mayor o menor intensidad, con las reglas normativas y jurisprudenciales por las cuales la consulta no podía prosperar.

Sin embargo, desde el considerando $10^{\circ}$ al $18^{\circ}$ bajo el título "Principio de colaboración entre los Poderes del Estado. Consideraciones frente a la excepcionalidad de la situación” afirma que "....amerita que este Tribunal formule algunas consideraciones adicionales, invocando el principio de colaboración inter poderes..." en razón de la "inédita situación planteada".

109. Considerando $5^{\circ}$ y $6^{\circ}$.

110. Rey c/ Rocha (revisión de sentencias arbitrarias); Siri y Kot (amparo); Halabi (acción colectiva); Fal (sentencia normativa ante un caso abstracto).

111. Considerandos $9^{\circ}, 10^{\circ}, 11^{\circ}, 12^{\circ}$ y $14^{\circ}$.

112. Considerandos $16^{\circ}$ y $17^{\circ}$. 
Luego de desarrollar argumentos jurídico políticos, y revisar los criterios jurisprudenciales del Alto Tribunal alrededor del interrogante original “...en consideración a las características de la presentación que se analiza, a la investidura de la presentante y a la excepcionalidad de las circunstancias que le sirven de contexto..."113 concluye con su aporte colaborativo "...que no le incumbe a este Tribunal expedirse sobre la forma en que el Senado debe resolver su trabajo en el futuro, en los siguientes dos sentidos: a) si de modo presencial o no presencial; y b) en la segunda hipótesis, si a partir de la interpretación o de la modificación de su Reglamento, tareas ambas que -por obedecer a su modo y forma de organización y funcionamiento- corresponden a la exclusiva competencia de la Cámara"114.

Sobre el final, en un punto IV RESUMEN, refuerza, a modo de consejo, el espíritu contributivo del voto, que se centró principalmente en recordarle al Senado la jurisprudencia de la CSJN en torno a los parámetros jurídicos que rodean el interrogante en consulta fundado en el principio de colaboración inter-poderes ${ }^{115}$; y acudiendo a un fraseario amistoso destaca el carácter político e ideológico planteado alrededor del debate ${ }^{116}$.

El escueto y preciso voto (desde la perspectiva jurídica el caso no traía complejidad) del Presidente del Tribunal Dr. Rosenkrantz, que denominamos el voto de las reglas decide rechazar in limine la acción, y no merece mayores comentarios.

No hay caso; no hay partes encontradas; no hay competencia originaria; es una cuestión abstracta y el juez argentino resuelve sobre causas o casos concretos. Las reglas son las reglas, la ley es la ley, agregamos nosotros ${ }^{117}$.

La lectura de este fallo me recordó una anécdota ${ }^{118}$. Hace muchos ańos, con motivo de un comentario que hice ha pedido de la editorial La Ley de una renovada edición del clásico Manual de Derecho Político del Dr. Carlos Fayt ${ }^{119}$, el recordado Ministro Decano me agradeció invitando un encuentro. El derecho constitucional y el rol del Tribunal no podían estar ausentes del diálogo. En un momento, ante una afirmación demasiado categórica de mi parte, el Profesor Fayt respondió con una frase que quedó grabada en mi memoria, y que pude corroborar a lo largo de los años. "Doctor, no se confunda. Todo es relativo ante esta Corte".

113. Considerando $14^{\circ}$.

114. Considerando $14^{\circ}$.

115. Considerando $15^{\circ}$ especialmente párrafos $3^{\circ}, 4^{\circ}, 5^{\circ}, 6^{\circ}$, y $8^{\circ}$; y considerando $17^{\circ}$.

116. Considerando $16^{\circ}$.

117. Parafraseando el título del libro de Andrés Rosler, La ley es la ley, (Buenos Aires: Katz editores, 2019).

118. Considero correcto utilizar ahora la primera persona

119. Comentario Bibliográfico de la obra "Manual de Derecho Político" (2 tomos) autor Carlos S. Fayt, (Buenos Aires: Editorial La Ley, 31 de diciembre de 2003). 


\section{X. ¿HACÍA UN SISTEMA MIXTO DE CONTROL?}

Soplan vientos de cambio. El Gobierno ha anunciado el próximo envío al Congreso de un proyecto de reforma judicial, y la constitución de una comisión asesora del Poder Ejecutivo sobre la conformación y competencia de la CSJN.

No vemos viable un cambio radical hacia un Tribunal Constitucional. Tentación que renace en el país recurrentemente. Nuestro sistema constitucional, como revisamos en este trabajo, se edificó sobre bases diferentes. Reglas de control e identidad distintas al modelo kelseniano.

Sin perjuicio de ello, cabe reconocer que por sobre nuestras preferencias jurídicas, disidencias o coincidencias, la CSJN ha ido perfilando un sistema de control federal propio, que si bien se origina históricamente en el judicial difuso y mantiene muchas de sus características, también evidencia diferencias marcadas con el modelo de origen, nacidas de la invocación de situaciones excepcionales, como en el presente fallo; y de la excesiva discrecionalidad (a nuestro modo de ver) que ha ido construyendo el Tribunal.

Por sobre el debate en torno al número de miembros de la Corte y su composición ¿Vamos hacia un sistema mixto de control de constitucionalidad que combine el control judicial difuso y algunos aspectos del concentrado?

Nuestra posición es proclive a regular algunos cambios, y así lo venimos sosteniendo en algunos trabajos $^{120}$.

Este es uno de los tantos temas -con final abierto- que en el marco del estado de excepción se debatirá en breve. Esperemos contar con un proyecto serio y responsable pensado en términos de prospectiva para un país que necesita indefectiblemente afianzar la seguridad jurídica y la credibilidad en el Poder Judicial si pretende desandar tantos años de desencuentros y retrocesos.

Los gobiernos deberían tener muy presente que la sociedad argentina muta con la velocidad del virus que hoy nos acecha, de la justificación pasiva de la excepción a la manifestación anárquica de la decepción.

\section{REFERENCIAS}

- $\quad$ Abraham Henry J. The judicial process. Séptima edición. Oxford University Press: mayo1998.

- Amaya, Jorge Alejandro. Control de Constitucionalidad. 2da. Edición actualizada y ampliada, $1^{\text {a }}$ reimpresión. Argentina: Astrea, 2017.

- Amaya Jorge Alejandro. Control de constitucionalidad y consulta legislativa ¿Hacia un sistema mixto de control federal? Tomado de https://es.scribd.com/document/471339767/Control-de-constitucionalidad-y-consultalegislativa-pdf

120. Jorge Alejandro Amaya, Democracia y Minoría Política, capítulo IX (Buenos Aires: Editorial Astrea, junio de 2014); y Control de Constitucionalidad (2da edición actualizada y ampliada), capítulo III, (Buenos Aires: Astrea, 2017). 
- Amaya Jorge Alejandro. Democracia y Minoría Política, capítulo IX. Buenos Aires: Editorial Astrea, junio de 2014.

- Amaya Jorge Alejandro. "El control jurisdiccional de los interna corporis acta”. Revista de Derecho Público, Control Judicial de la Jurisdicción Administrativa - II. Argentina, Santa Fe: Rubinzal Culzoni, Editores, (6 de mayo de 2011).

- Amaya Jorge Alejandro. ¿Está en crisis nuestro control federal de constitucionalidad? Argentina: Editorial La Ley, Suplemento especial 70 Aniversario, noviembre de 2005.

- Amaya Jorge Alejandro. Marbury v. Madison. Origen, argumentos y contraargumentos del control judicial de constitucionalidad. (5a edición). Argentina: Astrea, 2017.

- Amaya Jorge Alejandro. Director. Tratado de Control de Constitucionalidady Convencionalidad Tomo 2. "Sistemas Latinoamericanos", capítulo VI, 215-249. Buenos Aires: Astrea, 2018.

- Amaya Jorge Alejandro. "Un aspecto del Caso Corrientes. La Corte Suprema en deuda con el Federalismo". Boletín de la Asociación Argentina de Derecho Constitucional Nro. 95. Buenos Aires (marzo de 1994).

- $\quad$ Alexy, Robert. El concepto y la validez del derecho. Barcelona: Editorial Gedisa, 1994.

- Alexy, Robert. Teoría de los derechos fundamentales. Trad. Ernesto Garzón Valdés. Madrid: Centro de Estudios Constitucionales, 1993.

- Bidart Campos Germán J. La jurisprudencia obligatoria. Argentina: La Ley 2001-F 1492 - LLP.

- Bobbio, Norberto. Teoría general del Derecho. Bogotá: Temis,1997.

- CSJN, 6/9/90, “Dromi, José R. s/avocación en "Fontela, Moisés E. c/Estado nacional”, LL, 1990-E-97; LLC, 1990-854, y DJ, 1990-2-788. Otro ejemplo, casos "Fayt" y "Shiffrin.

- Constitución Política de la República de Chile, Tribunal Constitucional de Chile http://www.tribunalconstitucional.cl/wp/normas.

- Chacón Corado, Mauro R. "Guatemala, en Tratado de Control de Constitucionalidad y Convencionalidad”. (Jorge Alejandro Amaya, Director). Tomo 2, Sistemas Latinoamericanos, capítulo VII, pp. 251/282. Buenos Aires: Astrea, 2018.

- Dalla Vía, Alberto Modelo. Tribunales y sentencias constitucionales. www.juridicas.unam.mx 
- Díaz Ricci."Panorama y evolución del control de constitucionalidad en los Estados provinciales de Argentina". Revista Iberoamericana de Derecho Procesal Constitucional, n 11. México: Editorial Porrúa, (2009):184.

- Dworkin Ronald. Los derechos en serio, Trad. Marta Guastavino. Barcelona: Ariel, 1984, (reimpr. 2002).

-- Eguiguren Praeli, Francisco. Los Tribunales Constitucionales en Latinoamérica: una visión comparada. Buenos Aires, Argentina: Honrad Adenauer-Stiftunh AC. 2000.

- Fallos: 307-1379 "Provincia de Santiago del Estero c/Estado Nacional y/o Yacimientos Petrolíferos Fiscales - Acción de Amparo”, fallada el 20 de agosto de 1985.

- Fernández Segado. "La obsolescencia de la bipolaridad "modelo americano-modelo europeo-kelseniano" como criterio analítico del control de constitucionalidad y la búsqueda de una nueva tipología explicativa”. Parlamento y Constitución, (2002): 30.

- Ferrere Comella. Justicia Constitucional y Democracia. Madrid: Centro de Estudios Politicos y Constitucionales, 1997.

- García Mansilla, Manuel. Marbury v. Madison y los mitos acerca del control judicial de constitucionalidad, exposición del autor ante el Instituto de Derecho Constitucional de la Academia Nacional de Derechos y Ciencias Sociales. Buenos Aires: abril de 2020. https://doi.org/10.26422/RJA.2020.0101.gar

- García de Enterrí. El alcance del control judicial de las administraciones públicas en los Estados Unidos de América, 134.

- Garay Alberto. "La enseñanza del caso Marbury v. Madison. Academia”. Revista sobre enseñanza del Derecho, año 7, número 13, (2009): 121-136.

- Gómez Montoro Ángel José. “El control previo de constitucionalidad de proyectos de estatutos de Autonomía y demás leyes orgánicas”. Revista Española de Derecho Constitucional, Año 8, No 22, (enero-abril 1988).

- Hamilton Alexander, Jay John y Madison James. The Federalist o Federalist Papers, serie de 85 ensayos escritos entre octubre de 1787 y mayo de 1788. Los ensayos se publicaron de forma anónima, con el seudónimo "Publius", en varios periódicos del estado de Nueva York de la época. Primera edición encuadernada, con revisiones y correcciones de Hamilton, fue publicada en 1788 por los impresores J. y A. McLean. Segunda edición publicada con re visiones y correcciones de Madison, fue la primera en identificar cada ensayo por el nombre de su autor. por el impresor Jacob Gideon en 1818. Una última edición The Federalist, 
editado por Jacob E. Cooke (Middletown, Conn: Wesleyan University Press. 1961). Un texto electrónico de The Federalist que fue compilado para el Proyecto Gutenberg, puede revisarlo en https://guides.loc.gov/federalist-papers/full-text

- Hitter Juan Carlos. "La jurisdicción constitucional en Argentina”. García Belaunde Fernández Segado (coords). "La jurisdicción constitucional en Iberoamérica”. España: Editores Dykinson, 1997.

- Kelsen. "La garantía jurisdiccional de la Constitución (la justicia constitucional)". Revista Iberoamericana de Derecho Procesal Constitucional, $\mathrm{n}^{\circ} 10,3$.

- Linares, Sebastián. La (i) legitimidad democrática del control judicial de las leyes. Marcial Pons, Madrid: 2008.

- Manili Pablo (Director). Máximos Precedentes de la Corte Suprema de Justicia de la Nación. Capítulo VI, tomo I. Buenos Aires: Editorial La Ley, 2013.

- Morales Bustamante, Alejandro. Derecho procesal constitucional. Guatemala: Ediciones De Pereira, $2^{\mathrm{a}}$ ed, 2012.

- Prieto Sanchiz, Luis. Sobre Principios y Normas. Problemas del razonamiento jurídico. Madrid: Centro de Estudios Constitucionales, 1992.

- Ramírez Altamirano, Marina. Reforma a la Ley de la Jurisdicción Constitucional. Corte Suprema de Justicia, San José, Costa Rica, (2007): 234.

- Retortillo, Martín "Consideraciones sobre los tribunales constitucionales (El supuesto del Consejo Constitucional francés)”. Revista Española de Derecho Administrativo, n 15, 562.

- $\quad$ Rubio Llorente. “Tendencias actuales de la jurisdicción constitucional en Europa”. Manuel Fraga. Homenaje académico, vol. II, 1411 y 1416.

- Sagués,Nestor Pedro. Recurso extraordinario. T 1, Vol. 2. Buenos Aires, Argentina: Editorial Astrea, 2002.

- Sagués, Néstor Pedro. "Las sentencias constitucionales exhortativas". "Estudios Constitucionales", vol. 4, n 2, Centro de Estudios Constitucionales de Chile, (2006):189-202.

- $\quad$ Sagués, Néstor Pedro. “El control de constitucionalidad en la Argentina”, en SABSAY (dir) Constitución de la Nación Argentina, t. 4, 585 a 602.

- Suárez Crothers Christian G. Chile, en Tratado de Control de Constitucionalidady Convencionalidad. (Jorge Alejandro Amaya, Director), Tomo 2, "Sistemas Latinoamericanos”, capítulo IV, 131-183. Buenos Aires: Astrea, 2018. 
- Villaverde Menéndez Ignacio. El control previo de constitucionalidad de las normas con rango de ley. Crónica de un escéptico, Revista Catalana de dret públic. No 49, www.rcdp.cat

- Wardell Hogg, Peter. Constitutional Law of Canada. 5. ${ }^{\mathrm{a}}$ ed. Toronto: Carswell, 2007.

RECIBIDO: 20/10/2020

APROBADO: $10 / 11 / 2020$ 


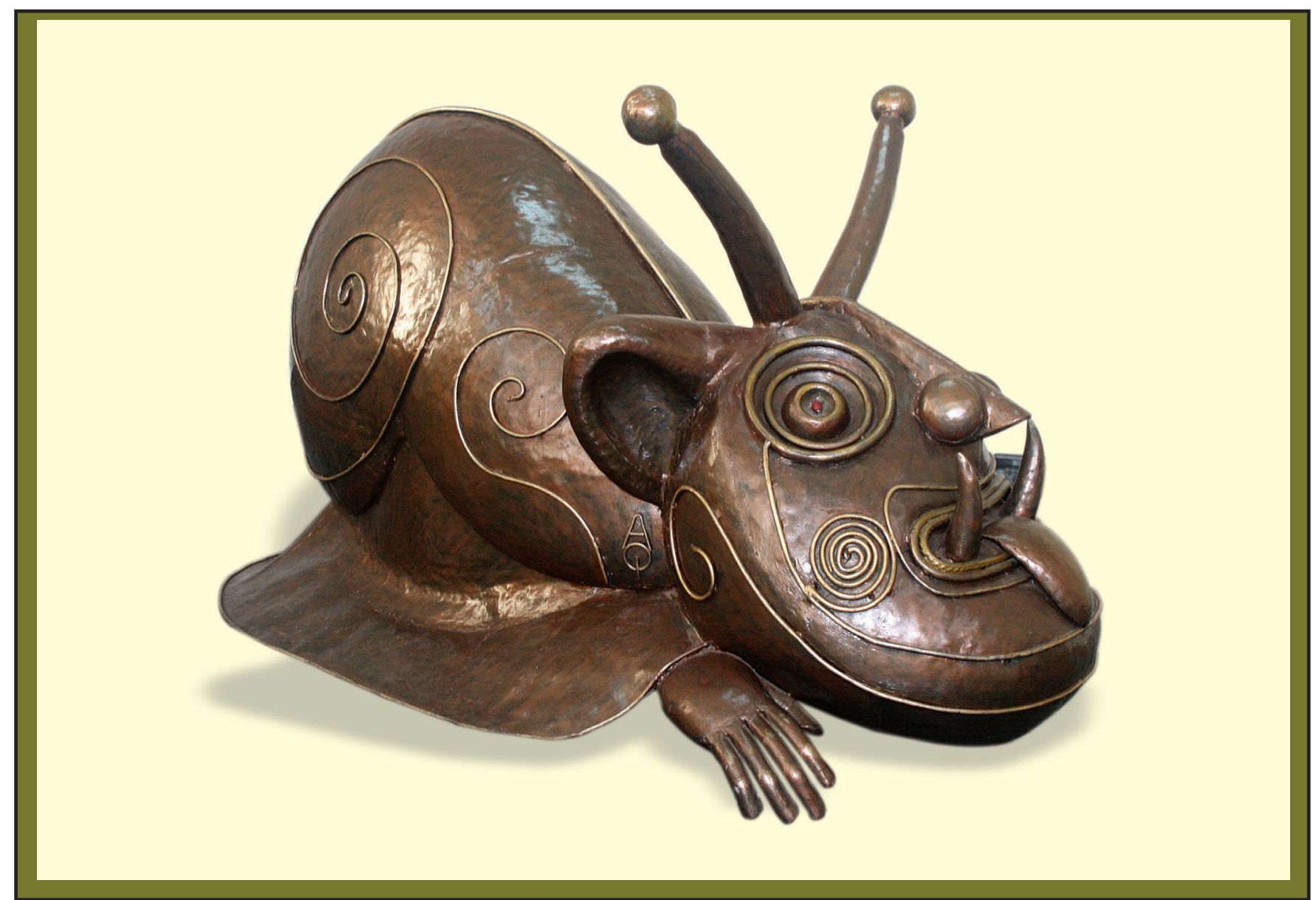

Manaraxmi tukunichu (Caracol). Hierro y bronce, 1998. Artista plástico peruano, Alberto Quintanilla (Cusco, 1934). 